ANL-6046

Chemistry - General

(TID-4500, 15th Ed.)

AEC Research and

Development Report

\author{
ARGONNE NATIONAL LABORATORY \\ P. O. Box 299 \\ Lemont, Illinois
}

\title{
OXIDATION OF ZIRCONIUM AND ZIRCONIUM ALLOYS
}

by

H. A. Porte, J. G. Schnizlein, R. C. Vogel, and D. F. Fischer

Chemical Engineering Division

September, 1959

Operated by The University of Chicago

under

Contract W-31-109-eng-38

$$
61+01
$$




\section{DISCLAIMER}

This report was prepared as an account of work sponsored by an agency of the United States Government. Neither the United States Government nor any agency Thereof, nor any of their employees, makes any warranty, express or implied, or assumes any legal liability or responsibility for the accuracy, completeness, or usefulness of any information, apparatus, product, or process disclosed, or represents that its use would not infringe privately owned rights. Reference herein to any specific commercial product, process, or service by trade name, trademark, manufacturer, or otherwise does not necessarily constitute or imply its endorsement, recommendation, or favoring by the United States Government or any agency thereof. The views and opinions of authors expressed herein do not necessarily state or reflect those of the United States Government or any agency thereof. 


\section{DISCLAIMER}

Portions of this document may be illegible in electronic image products. Images are produced from the best available original document. 


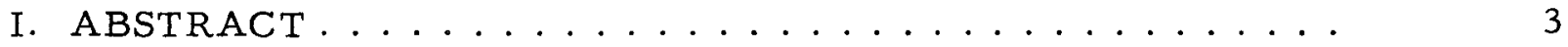

II. INTRODUCTION. ...................... 4

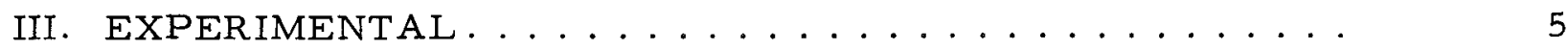

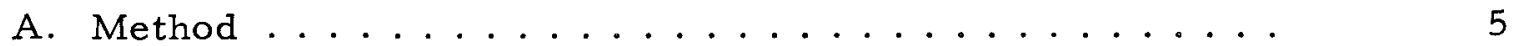

B. Materials..................... 7

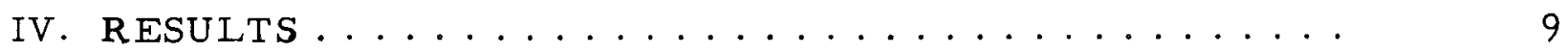

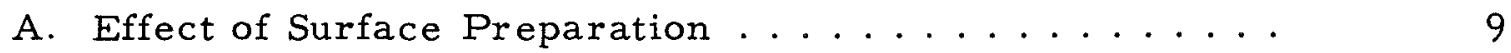

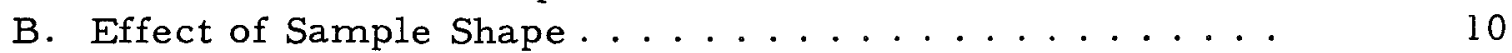

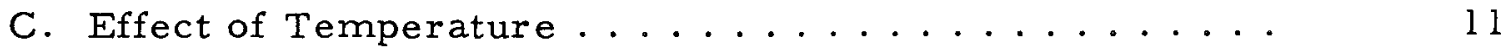

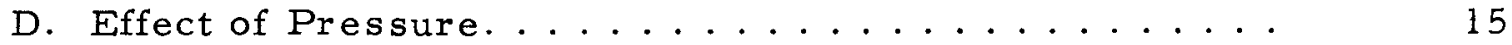

E. Effect of Additives to Zirconium ........... 15

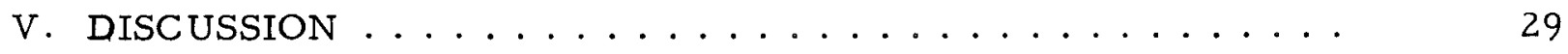

A. Literature and Theoretical Considerations. . . . . . . . 29

B. Correlation of Isothermal Rate Data with Theory ..... 31

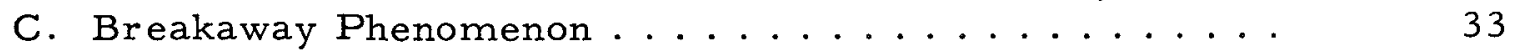

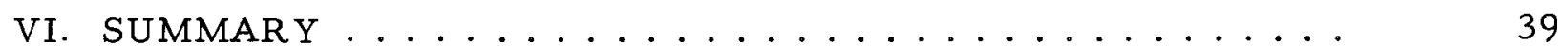

VII. ACKNOWLEDGEMENTS ..................... 40

VIII. REFERENCES ....................... 41 


\title{
OXIDATION OF ZIRCONIUM AND ZIRCONIUM ALLOYS
}

\author{
by
}

H. A. Porte, J. G. Schnizlein, R. C. Vogel, and D. F. Fischer

\section{ABSTRACT}

The oxidation of zirconium was investigated in the temperature range 400 to $900 \mathrm{C}$ at oxygen pressures of 50,200 , and $800 \mathrm{~mm}$. The reaction rate of massive (parallelepiped) samples was best expressed by the cubic rate law. At an oxygen pressure of $200 \mathrm{~mm}$ the activation energy was calculated to be $42.7 \mathrm{kcal}$ per mole, and the cubic rate constant in $(\mu \mathrm{g} \text { per sq } \mathrm{cm})^{(3)}$ per minute can be expressed as

$$
\mathrm{k}=\left(5.94 \times 10^{16}\right) \mathrm{e}^{-42,700 / \mathrm{RT}} \text {. }
$$

The oxidation rate was found to be relatively insensitive to various types of surface preparations in the temperature range 400 to $700 \mathrm{C}$. No dependence of reaction rate on oxygen pressure was observed. The cubic rate law also was obeyed by foil specimens at $700 \mathrm{C}$; however, the rate constants were slightly larger than values obtained from parallelepiped samples.

The oxidations of zirconium binary alloys containing nominally one, two, and four atom per cent additives of aluminum, beryllium, carbon, chromium, cobalt, copper, hafnium, iron, lead, molybdenum, nickel, niobium, platinum, silicon, tantalum, tin, titanium, tungsten, uranium, and vanadium were studied at $700 \mathrm{C}$ and $200 \mathrm{~mm}$ oxygen. The alloys were grouped according to four types of oxidation behavior. Two groups consisted of alloys which oxidized according to the cubic rate law (Group I) or parabolic rate law (Group II) and did not exhibit breakaway phenomena. The other groups were alloys which initially oxidized according to the cubic rate law (Group III) or parabolic rate law (Group IV) but later exhibited breakaway oxidation phenomena. For alloys of those additives which are soluble in zirconium the initial oxidation rates are explained according to a valency effect in terms of the Wagner-Hauffe theory of alloy oxidation. For additives insoluble in zirconium, no single theory is felt to be adequate. The breakaway phenomena observed for many of the alloys is explained in terms of a 15 per cent deviation of the additive ionic radius from the ionic radius of $\mathrm{Zr}^{4+}$. Some $\mathrm{X}-\mathrm{ray}$ and electron diffraction studies, which indicate that for zirconium and some of its alloys the breakaway occurs as a result of a polymorphic transformation in the zirconium dioxide film, were made. 


\section{INTRODUCTION}

The reaction of zirconium with oxygen at high temperatures has been studied by several investigators.(1-7) A comparison of the results shows discrepancies concerning which rate law, cubic or parabolic, best describes the oxidation kinetics. For example, Gulbransen and Andrew (1) studied the reaction on foil specimens between 200 and $425 \mathrm{C}$ and reported that the parabolic rate law fitted their data. But Belle and Mallett $(2)$ showed by replotting the same data in a different fashion that the cubic rate law was obeyed - implying that the interpretation of data can be somewhat arbitrary in some cases.

In another study $(3)$ between 400 and $800 \mathrm{C}$, Gulbransen and Andrew found that the method of surface preparation influenced the reaction kinetics. Foil specimens which were mechanically polished obeyed the cubic rate law, whereas chemically polished specimens obeyed the parabolic rate law.

There is some reason to suspect that the sizes and shapes of samples may influence the reaction kinetics. Belle and Mallett(2) studied the oxidation reaction on rod specimens between 575 and $950 \mathrm{C}$ and found that the cubic rate law fit the data. On foil specimens in approximately the same temperature range, Cubicciotti, (4) Fassell, (5) and Garibotti, Green and Baldwin $(6)$ observed the parabolic rate law.

There is even some evidence that the particular rate law which is followed depends upon the temperature range. In a recent study by Kofstad, (7) zirconium was oxidized under conditions of linearly increasing temperature. It was shown that between 650 and $950 \mathrm{C}$ the cubic rate law was obeyed and between 950 and $1100 \mathrm{C}$ the parabolic rate law fit the data.

Some investigatores $(1,4,5)$ have studied the effect of pressure. The concensus was that pressure has little or no effect on the reaction of zirconium with oxygen.

The reported work on the reaction of zirconium alloys with oxygen has been confined previously to zirconium-tin alloys for which important uses have been found in the field of nuclear reactor engineering. Mallett and Albrecht $(8)$ have studied the oxidation of 1.5 and 2.5 weight per cent tin alloys at high temperatures. Gulbransen and Andrew (9) studied the reaction of the Zircaloy -2 and $-3 a$ with oxygen. In both investigations $t$ in was found to increase the rate of oxidation.

Nitrogen also reacts with zirconium, but at a much slower rate than has been found for the reaction with oxygen. Several studies $(1,6,10-12)$ have been made and most investigators agree that the parabolic rate law is obeyed. The product of the reaction at all temperatures has been identified as golden-yellow zirconium nitride. There is some evidence(l) that the presence of small traces of oxygen in the nitrogen noticeably accelerates the rate of the reaction. 
Some work has also been done on the reaction of zirconi$\operatorname{um}^{(6,10,13,14)}$ and zirconium alloys $(13,15-17)$ with air. In general, the reaction rate is higher in air than in either nitrogen or oxygen alone. Both zirconium dioxide and zirconium nitride have been identified as products of the air reaction. The data on alloy oxidation indicate that in most cases additives to the metal do not improve the resistance of zirconium to oxidation in air.

The purpose of this study was to investigate the fundamental processes involved in the oxidation mechanism. One phase of the program was concerned with the effects of surface preparation, sample shape, temperature, and oxygen pressure on the reaction rate. However, the major effort was devoted to determining the effect of various additives on the oxidation of zirconium. This was accomplished by studying the kinetics of the reaction of numerous zirconium alloys with oxygen at $700 \mathrm{C}$. Simultaneously a study was made of the structure of the oxide films produced during the oxidations.

\section{EXPERIMENTAL}

A. Method

The reactions of zirconium and zirconium alloys with oxygen were measured by a volumetric method. Essentially the apparatus consisted of a reaction chamber which was connected through stopcocks to a pressure regulator, a gas buret,

Figure 1

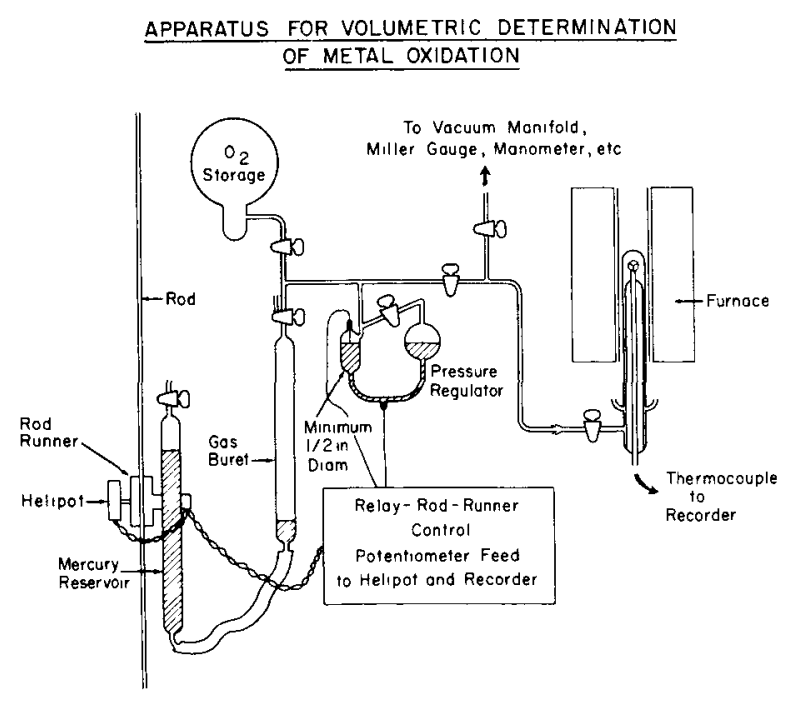
and a vacuum system (Figure l). With the exception of the reaction tube, which was made of quartz, the apparatus was made entirely of Pyrex. The system was evacuated by a two-stage glass mercurydiffusion pump backed by a mechanical pump.

The reaction tube, which was supported in a vertically mounted resistance furnace, consisted of two parts which were joined by a means of a greased ball joint (below the furnace and cooled by a jet of air). Sealed to the lower section was an evacuated inner tube which extended well into the furnace hot zone and filled most of the cross-sectional 
area of the reactor, thus minimizing the volume of gas exposed to the temperature gradient at the lower end of the furnace. The metal sample rested on top of a long thermocouple well which passed through the center of the inner tube of the reactor.

The reactor was joined by a greased, ground glass joint to a $2-\mathrm{mm}$ capillary line leading to the pressure regulator and the gas buret. The water-jacketed gas buret was connected with a flexible tube to a similar buret which served as a mercury reservoir. As the sample consumed oxygen, the pressure in the reactor decreased slightly, causing the mercury in the pressure regulator to make contact with a sealed-in tungsten wire. A zero-current relay closed the power circuit to a motorized rod runner which raised the mercury reservoir. Mercury flowed into the gas buret, increased the pressure in the system, and the electrical contact in the pressure regulator was opened.

Coupled with the rod runner was a precision, helically wound potentiometer (Helipot) which translated the position of the reservoir into an electrical potential. Changes of this potential, recorded on a strip chart potentiometer-recorder, were proportional to the movement of the reservoir, and thus were proportional to the volume of oxygen consumed by the sample. By application of the gas laws and from the measured sample area the consumption could be expressed in micrograms of oxygen per square centimeter of surface. After calibration, sensitivities from 0.05 to $12 \mu \mathrm{g}$ per sq $\mathrm{cm}$ were determined, depending on oxygen pressure and the choice of buret diameter.

The volumetrically measured total oxygen consumed has been exactly verified on several occasions by weighing the sample on an analytical balance before and after oxidation.

The operation of the volumetric apparatus was checked by the use of a constant-rate leak connected to a vacuum pump in place of an oxygenconsuming sample. The leak was constructed by sealing a 19-gage copper wire, about $5 \mathrm{~cm}$ in length, inside a section of Pyrex tubing. On cooling, the difference in coefficients of expansion of copper and Pyrex produced a very small annular space between the wire and the collapsed tube. The reproducible observed linear rate indicated that the apparatus was functioning satisfactorily.

A hinged-type Hevi-duty combustion tube furnace was used for runs at $700 \mathrm{C}$ and below, while a platinum-wound Marshall furnace was used for runs above $700 \mathrm{C}$. The furnace temperature was controlled to \pm 3 degrees $\mathrm{C}$ by a proportional controller operated by the output from a thermocouple located at sample level outside, but near, the reactor.

$$
0 \div
$$


Before the start of the run the specimen and reaction tube were evacuated at room temperature for 16 hours at pressures of less than $10^{-5} \mathrm{~mm}$ to minimize the reaction of zirconium with gases present in the vacuum system during the heat-up period. After establishing thermal equilibrium at the desired temperature, the run was started by closing off the high-vacuum line and admitting the oxygen to the reaction chamber. Pressure equilibrium was established within 30 seconds, thus allowing the first data point to be obtained. By subtracting the volume of oxygen neces sary to fill the reaction tube, obtained in earlier blank runs, it was possible to calculate the amount of oxygen consumed by the sample from zero time.

Unless otherwise specifically indicated, all runs were made on specimens which were machined parallelepipeds, $1 \times 1 \frac{1}{2} \times 2 \mathrm{~cm}$. Freshly polished specimens were used for each run.

The $\mathrm{X}$-ray diffraction investigations* of the oxide films were carried out by means of a Norelco X-ray diffraction powder camera $(114.59 \mathrm{~mm}$ in diameter). For electron diffraction investigations** an RCA electron diffraction unit Model EMU-2 was used.

\section{B. Materials}

Table I shows the principal impurities in the arc-melted Grade I crystal bar zirconium used in the oxidation studies on pure zirconium. These studies included the effects of surface preparation, temperature, pressure, and sample shape.

To study the effect of impurities on the oxidation properties of zirconium a series of binary alloys with additives at three nominal concentration levels - 1, 2, and 4 atom per cent - was obtained.*** The actual analyzed alloy compositions are given in Table II. Arc - melted Grade I crystal bar zirconium having the analysis also given in Table I was used in preparation of these alloys.

The oxygen used in these experiments was taken directly from the tank without further purification. Mass spectrographic and dew-point analyses showed the following typical impurities (in volume per cent): argon 0.1 ; carbon dioxide 0.06 ; nitrogen 0.2 ; and water 0.005 .

* Performed by D. S. Flikkema.

** Performed by H. Knott and M. Mueller

*** Zirconium binary alloys were prepared by Oregon Metallurgical Corporation, Albany, Oregon 
TABLE I

Analysis of Zirconium

Chemical analyses for $\mathrm{C}, \mathrm{H}, \mathrm{N}, \mathrm{O}$; all other elements determined by spectrographic analyses

$\begin{array}{lccc}\text { Element } & \begin{array}{c}\text { Zirconium Used in } \\ \text { Oxidation Studies } \\ \text { (ppm) }\end{array} & \begin{array}{c}\text { Zirconium Used as Base } \\ \text { Metal for Alloys } \\ \text { (ppm) }\end{array} \\ \mathrm{Ag} & <1 & 1 \\ \mathrm{Al} & 10 & <10 \\ \mathrm{~B} & <0.1 & 0.5 \\ \mathrm{C} & 79 & 19 \\ \mathrm{Cr} & 1 & 5 \\ \mathrm{Cu} & 5 & 100 \\ \mathrm{Fe} & 800 & 80 \\ \mathrm{H} & - & 0.6 \\ \mathrm{Hf} & <1000 & <500 \\ \mathrm{Mg} & <1 & 15 \\ \mathrm{Mn} & 1 & 1 \\ \mathrm{~N} & 23 & 11 \\ \mathrm{~N} 1 & 100 & <50 \\ \mathrm{O} & 185 & 77 \\ \mathrm{~Pb} & 4 & 15 \\ \mathrm{~S} 1 & 50 & 50\end{array}$

TABLE II

Composition of Zirconium Binary Alloys

\begin{tabular}{|c|c|c|c|c|c|c|c|}
\hline \multirow{3}{*}{$\begin{array}{c}\text { Alloy } \\
\text { Additive }\end{array}$} & \multirow{3}{*}{$\frac{\text { Nominal a/o }}{\text { Analyzed }}$} & \multicolumn{6}{|c|}{ Composition } \\
\hline & & \multicolumn{2}{|c|}{1} & \multicolumn{2}{|c|}{2} & \multicolumn{2}{|c|}{4} \\
\hline & & $a / o$ & $\mathrm{w} / \mathrm{o}$ & $\mathrm{a} / \mathrm{o}$ & $w / o$ & $a / o$ & $\mathrm{w} / \mathrm{o}$ \\
\hline Copper & & 1.08 & 0.75 & 1.84 & 1.28 & 360 & 2.53 \\
\hline Nickel & & 0.91 & 0.59 & 2.48 & 1.61 & 4.22 & 2.75 \\
\hline Beryllium & & 0.90 & 0.09 & 209 & 0.21 & 4.23 & 0.44 \\
\hline Hafnium & & 1.03 & 2.00 & 2.22 & 4.25 & 4.08 & 765 \\
\hline Chromium & & 0.77 & 0.44 & 1.63 & 0.93 & 3.61 & 2.05 \\
\hline Cobalt & & 0.86 & 0.55 & 2.49 & 1.62 & 3.72 & 2.44 \\
\hline Iron & & 1.09 & 0.67 & 1.98 & 1.22 & 3.95 & 2.46 \\
\hline Tungsten & & 0.68 & 1.34 & 1.96 & 3.87 & -- & -- \\
\hline Tantalum & & 1.04 & 2.05 & 1.78 & 3.47 & 3.54 & 6.70 \\
\hline Uranium & & 0.89 & 2.30 & 1.76 & 4.48 & 3.52 & 8.71 \\
\hline Platınum & & 1.08 & 2.28 & 2.04 & 4.27 & 4.22 & 8.61 \\
\hline Molybdenum & & 1.03 & 1.08 & 2.34 & 2.45 & 3.65 & 3.83 \\
\hline Tin & & 0.96 & 1.25 & 1.68 & 2.18 & 3.60 & 4.63 \\
\hline Lead & & 0.58 & 1.29 & 1.62 & 3.61 & 4.00 & 8.64 \\
\hline Aluminum & & 1.42 & 0.42 & 2.15 & 0.65 & 3.62 & 1.10 \\
\hline Silicon & & 0.80 & 0.25 & 1.94 & 0.60 & 3.60 & 1.14 \\
\hline Vanadium & & 1.01 & 0.56 & 1.84 & 1.04 & 3.88 & 2.20 \\
\hline Carbon & & 0.65 & 0.086 & 1.64 & 0.22 & 3.72 & 0.50 \\
\hline Niobium & & 0.60 & 0.61 & 1.82 & 1.85 & 3.82 & 3.89 \\
\hline Titanium & & 1.08 & 0.57 & 2.12 & 1.11 & 4.16 & 2.14 \\
\hline
\end{tabular}

$6 \vdots$ 


\section{RESULTS}

The experimental approach in these studies was as follows. First, preliminary work was done to determine the influence of such variables as surface preparation and sample form. Next, temperature- and pressuredependence studies covering the temperature range from 400 to $900 \mathrm{C}$ at three pressures - 50, 200, and $800 \mathrm{~mm}$ - were undertaken. Finally, a study was made concerning the effect of additives.

\section{A. Effect of Surface Preparation}

To determine the effect of surface preparation on reaction rate a number of runs, using samples polished by different techniques, were made. This study was originally done at $700 \mathrm{C}$ but when, during the course of this work, a report by Gulbransen and Andrew(1) gave some evidence for a dependence of reaction rate on surface preparation in the 400 to $600 \mathrm{C}$ temperature range, the study was extended to lower temperatures. According to the results of Gulbransen and Andrew, 0.127-mm (5-mil), chemically polished samples obeyed the parabolic rate law, whereas mechanically abraded samples obeyed the cubic rate law.

Table III presents a summary of the data from the present study, comparing runs with different polishing techniques. For each method of polishing at every temperature from two to four runs were performed, and the average results are listed.

TABLE III

Effect of Surface Preparation on the Reaction of Zirconium with Oxygen

(Oxygen Pressure, $200 \mathrm{~mm}$ )

\begin{tabular}{|c|c|c|c|}
\hline $\begin{array}{c}\text { Temperature } \\
\text { (C) }\end{array}$ & Surface Preparation & $\begin{array}{l}\text { Slope of } \\
\text { Log-Log } \\
\text { Plot }(1 / n) \\
\end{array}$ & $\begin{array}{c}\text { Cubic Rate } \\
\text { Constant, } \mathrm{k} \\
{\left[(\mu \mathrm{g} / \mathrm{sq} \mathrm{cm})^{3} / \mathrm{m} \mathbf{n}\right]}\end{array}$ \\
\hline 400 & Mechanical Polish - 600 grit & $0.29 \pm 0.00$ & $(11 \pm 5.2) \times 10^{2}$ \\
\hline 400 & Chemical Polisha & $0.36 \pm 0.01$ & $(5.9 \pm 2.0) \times 10^{2}$ \\
\hline 500 & Mechanical Polish - 600 grit & $0.31 \pm 0.01$ & $(3.5 \pm 0.1) \times 10^{4}$ \\
\hline 500 & Chemical Polish & $0.33 \pm 0.01$ & $(2.1 \pm 0.3) \times 10^{4}$ \\
\hline 600 & Mechanical Polish - 600 grit & $0.33 \pm 0.01$ & $(1.2 \pm 0.4) \times 10^{6}$ \\
\hline 600 & Chemical Polish & $0.37 \pm 0.01$ & $(1.1 \pm 0.3) \times 10^{6}$ \\
\hline 700 & Mechanical Polish - 600 grit & $0.34 \pm 0.02$ & $(1.6 \pm 0.2) \times 10^{7}$ \\
\hline 700 & Mechanical Polish $-0.5 \mu$ & $0.36 \pm 0.01$ & $(1.5 \pm 0.1) \times 10^{7}$ \\
\hline 700 & Attack Polıshb & $0.36 \pm 0.02$ & $(1.3 \pm 0.1) \times 10^{7}$ \\
\hline 700 & Chemical Polish & $0.35 \pm 0.01$ & $(1.5 \pm 0.2) \times 10^{7}$ \\
\hline
\end{tabular}

a Composition of chemical polish solution: 45 parts $\mathrm{H}_{2} \mathrm{O}, 45$ parts $\mathrm{HNO}_{3}$ (conc), and 10 parts $\mathrm{HF}(48 \%)$

b

Mechanical polish through $0.5 \mu \mathrm{in}$ which $1 \mathrm{ml} \mathrm{HF}(48 \%)$ and $0.5 \mathrm{ml} \mathrm{HNO}_{3}$ (conc) are added to $98.5 \mathrm{ml}$ of Linde $\mathrm{A}$ abrasive 
The 600-grit mechanical polish was accomplished by grinding the zirconium with different grades of silicon carbide paper and finally finishing with the 600-grit paper. The lubricant used was water.

The 0.5-micron mechanical polish was simply an extension of the 600 -grit polish with Linde A aluminum oxide abrasive on a Miracloth lap. The polishing was continued until all of the visible $600-$ grit scratches were removed.

The attack polishing technique was a variation of the 0.5 -micron mechanical polishing method in which $1 \mathrm{ml}$ of hydrofluoric acid $(48 \%)$ and $0.5 \mathrm{ml}$ of nitric acid (conc) are added to $98.5 \mathrm{ml}$ of the Linde A abrasive.

The preparation utilizing a chemical polish consisted of grinding the zirconium to a $600-$ grit finish and subsequently immersing the metal in a solution of 10 parts hydrofluoric acid (48\%), 45 parts nitric acid (conc), and 45 parts water by volume. After a few seconds the metal was removed from the solution, dipped into water, and finally rinsed with alcohol.

- All methods of polishing gave reproducible data which were best expressed in terms of the cubic rate law. For the range from 400 to $600 \mathrm{C}$, the log-log slopes obtained from chemically polished samples were slightly higher, and the cubic rate constants were slightly lower, than those obtained from mechanically polished samples. At $700 \mathrm{C}$ both log-log slopes and cubic rate constants were insensitive to sample pretreatment.

Thus, it was concluded that for massive samples $\left(1 \times 1 \frac{1}{2} \times 2-\mathrm{cm}\right.$ parallelepipeds) the rate of the oxidation reaction in the temperature range from 400 to $700 \mathrm{C}$ is practically independent of surface preparation. Therefore, since the 600-grit mechanical polish was found to be the quickest and simplest procedure, it was used in all of the pure zirconium runs and in the alloy studies.

This work does not necessarily contradict that of Gulbransen and Andrew, since their experiments were made on 5-mil sheet, whereas these experiments were carried out on $1 \times 1 \frac{1}{2} \times 2-\mathrm{cm}$ parallelepipeds. However, it does indicate that the dependence of reaction rate kinetics upon surface preparation which they found for 5-mil sheet cannot be extrapolated freely to thicker specimens.

\section{B. Effect of Sample Shape}

In going from massive metal to foil the surface area per unit weight is increased. At the same time several other factors which may possibly influence the rate are affected. The metallurgical conditions of the metal, i.e., grain size, crystal orientation, strains, etc., are changed. Also, certain impurities may be introduced during the rolling operations. It would be 
necessary to separate and study each of these variables to investigate thoroughly the effect of foil samples on reaction rate. Such a study was beyond the scope of this investigation.

However, two runs were made on $0.25-\mathrm{mm}$ (10-mil) foils which had been cold rolled from sponge zirconium. The foil samples were polished through 600 grit and run at $700 \mathrm{C}$ and $200 \mathrm{~mm}$ oxygen pressure. The slopes of the log-log plots were 0.35 in both cases, in good agreement with parallelepiped samples. The cubic rate constants were found to be $2.3 \times 10^{7}$ and $2.8 \times 10^{7}(\mu \mathrm{g} \text { per sq } \mathrm{cm})^{3}$ per $\mathrm{min}$, somewhat larger than values obtained from parallelepiped samples. The results would indicate that at the temperature studied $(700 \mathrm{C})$ the rate law is not affected by a change in sample shape, but that foil samples oxidize somewhat faster than parallelepiped samples. Examination of the product immediately after one of the foil runs revealed an adherent black oxide film similar to those formed on the parallelepiped samples.

\section{Effect of Temperature}

Oxidation rates were measured at various temperatures in the range from 400 to $900 \mathrm{C}$ at an oxygen pressure of $200 \mathrm{~mm}$. Plots of the $\log$ of the weight gain versus the log of time for typical runs at these temperatures are given in Figure 2. The straight lines indicate agreement with the general rate expression $W^{n}=k t$. The values of $n$ can readily be obtained since the slope of the line on this type of plot is $1 / n$.

Figure 2

EFFECT OF TEMPERATURE

ON THE REACTION OF ZIRCONIUM WITH OXYGEN

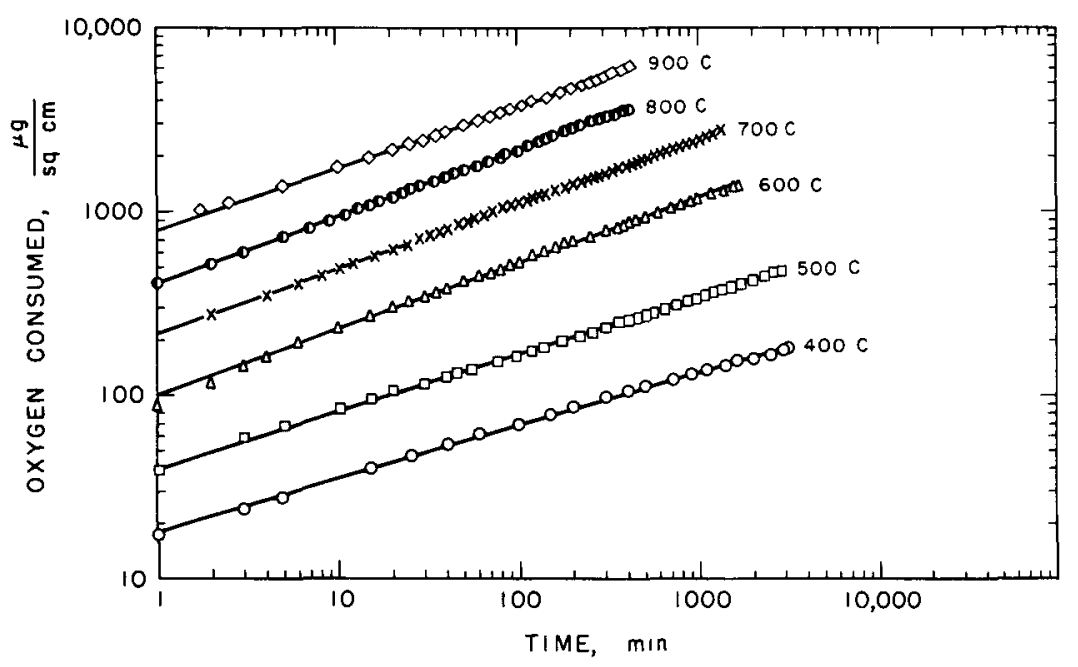

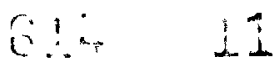


From the values of $1 / \mathrm{n}$ listed in $\mathrm{Table}$ IV it is seen that the reaction rate is best expressed by the cubic rate law, $W^{3}=k t$. The value of $1 / n$ increased slightly on raising the temperature from 400 to $800 \mathrm{C}$ and then dropped a bit at $900 \mathrm{C}$. There is no apparent reason for the increasing trend in the value of $1 / \mathrm{n}$; however, the drop from 800 to $900 \mathrm{C}$ may be attributed to the transformation from $\alpha$ to $\beta$ zirconium, which occurs at $862 \mathrm{C}$. The cubic rate law constants listed in Table IV were obtained from plots of $W$ versus $t^{1 / 3}$. Typical runs at different temperatures are shown plotted in this manner in Figure 3.

TABLE IV

Cubic Rate Constants for the Reaction of Zirconium with Oxygen

(Oxygen Pressure, $200 \mathrm{~mm}$ )

\begin{tabular}{|c|c|c|c|}
\hline $\begin{array}{c}\text { Temperature } \\
\text { (C) }\end{array}$ & $\begin{array}{l}\text { Length of Run } \\
\text { (min) }\end{array}$ & $\begin{array}{l}\text { Slope of } \\
\text { Log-Log } \\
\text { Plot, } 1 / \mathrm{n} \\
\end{array}$ & $\begin{array}{c}\text { Cubic Rate } \\
\text { Constant, } \mathrm{k} \\
{\left[(\mu \mathrm{g} \mathrm{sq} \mathrm{cm})^{3} / \mathrm{min}\right]}\end{array}$ \\
\hline 400 & 3235 & 0.29 & $1.6 \times 10^{3}$ \\
\hline 400 & 4275 & 0.29 & $5.6 \times 10^{2}$ \\
\hline 500 & 4238 & 0.30 & $3.5 \times 10^{4}$ \\
\hline 500 & 2860 & 0.32 & $3.6 \times 10^{4}$ \\
\hline 600 & 1660 & 0.33 & $1.6 \times 10^{6}$ \\
\hline 600 & 4250 & 0.34 & $8.9 \times 10^{5}$ \\
\hline 700 & 1415 & 0.29 & $1.5 \times 10^{7}$ \\
\hline 700 & 1400 & 0.31 & $1.8 \times 10^{7}$ \\
\hline 700 & 1400 & 0.33 & $1.5 \times 10^{7}$ \\
\hline 700 & 1400 & 0.33 & $2.0 \times 10^{7}$ \\
\hline 700 & 1323 & 0.35 & $1.7 \times 10^{7}$ \\
\hline 700 & 400 & 0.36 & $1.6 \times 10^{7}$ \\
\hline 700 & 1345 & 0.36 & $1.3 \times 10^{7}$ \\
\hline 700 & 1408 & 0.36 & $1.4 \times 10^{7}$ \\
\hline 800 & 5645 & 0.36 & $1.3 \times 10^{8}$ \\
\hline 800 & 400 & 0.37 & $1.3 \times 10^{8}$ \\
\hline 800 & 413 & 0.38 & $1.3 \times 10^{8}$ \\
\hline 800 & 415 & 0.39 & $1.3 \times 10^{8}$ \\
\hline 900 & 400 & 0.32 & $5.3 \times 10^{8}$ \\
\hline 900 & 418 & 0.34 & $5.3 \times 10^{8}$ \\
\hline
\end{tabular}

$$
6 \div 4 \quad 12
$$


Figure 4 represents a plot of the log of the cubic rate constants versus $1 / T$ for temperatures in the range from 400 to $900 \mathrm{C}$. The position of the best straight line through these points was determined by the method of least squares. The activation energy, obtained using the Arrhenius-type equation, $\mathrm{k}=\mathrm{Ae}-\Delta \mathrm{E} / \mathrm{RT}$, was $42.7 \pm 0.7 \mathrm{kcal}$ per mole. The corresponding rate constant for the reaction in $(\mu \mathrm{g} \text { per sq } \mathrm{cm})^{3}$ per min was

$$
\mathrm{k}=\left(5.94 \times 10^{16}\right) \mathrm{e}^{-42,700 / \mathrm{RT}},
$$

where the constant $A$ is $5.94 \times 10^{16}$. This shows good agreement with the results of Belle and Mallett (2) who also observed the cubic rate law and obtained an activation energy of $47.2 \mathrm{kcal}$ per mole.

Figure 3

Figure 4

EFFECT OF TEMPERATURE ON THE REACTION OF ZIRCONIUM WITH OXYGEN

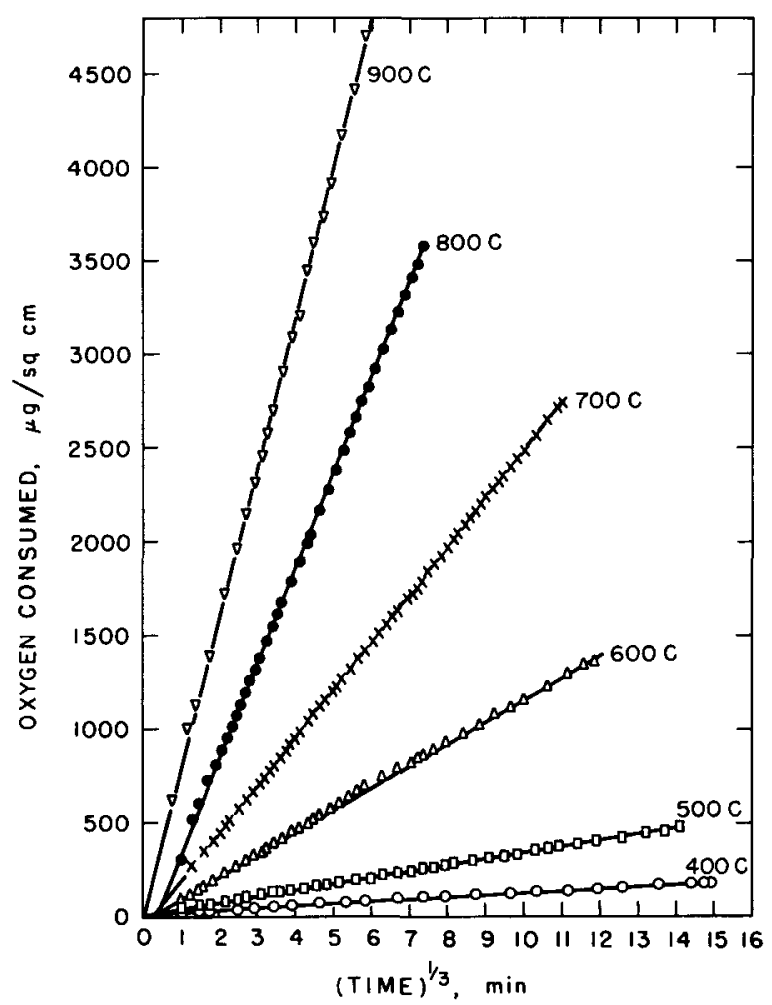

REACTION OF ZIRCONIUM WITH OXYGEN (VARIATION OF REACTION RATE CONSTANT WITH TEMPERATURE)

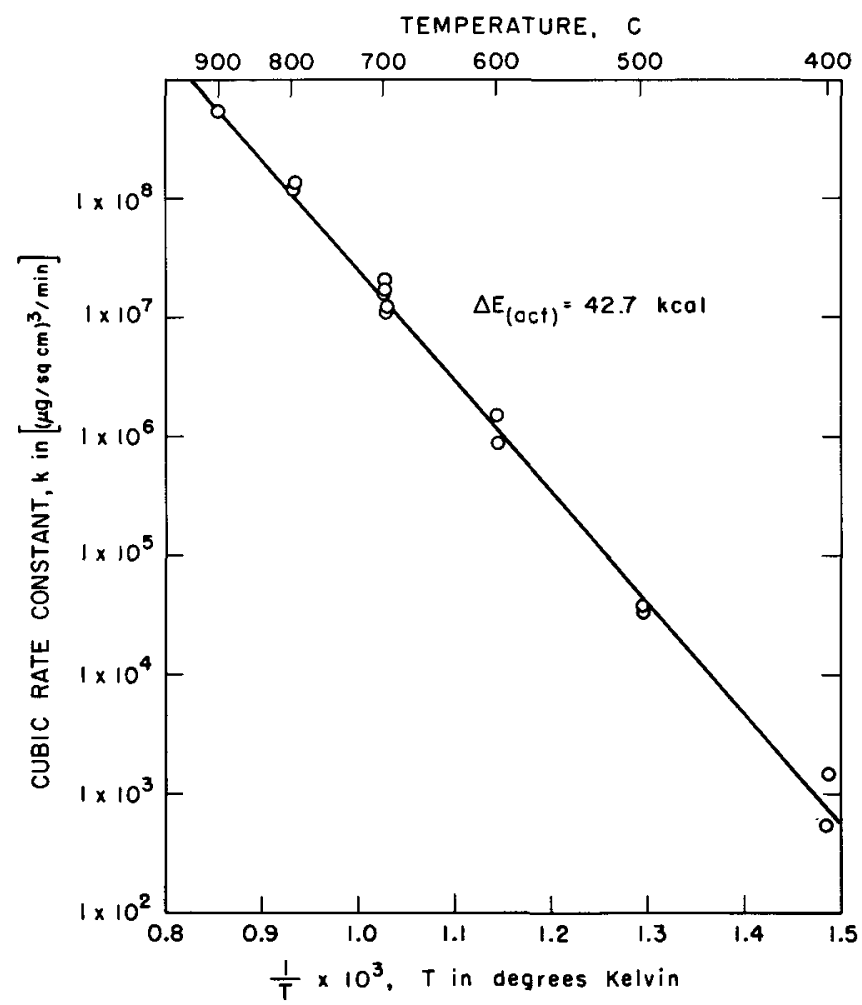

The lengths of the runs, as indicated in Table IV, varied from a minimum of 400 minutes to several thousand minutes in some cases; however, the run length had no effect on either the log-log slopes or the cubic rate constants. No breakaway phenomena were observed in any of the runs, even at the higher temperatures. One run at $800 \mathrm{C}$ was carried out for longer than 5600 minutes without giving any sign of a breakaway. 
The reaction produced a shiny blue-black oxide at all temperatures. A few white specks were observed on the surface of the oxide at $900 \mathrm{C}$.

Because of the high solubility of oxygen in zirconium (29 atom per cent), the reaction is somewhat complicated. A sample which had been run at $900 \mathrm{C}$ was mounted in Bakelite, polished, and then photomicrographed (see Figure 5). The thickness of zirconium dioxide, as measured from the photomicrograph, was 22 microns; the thickness calculated from the amount of oxygen consumed was 41 microns, based on the assumptions that (1) the ratio of the real to measured surface area was one and (2) the only product formed was zirconium dioxide having a density of 5.73 grams per cc. Evidently an appreciable solution of zirconium dioxide in zirconium takes place at $900 \mathrm{C}$.

Figure 5

PHOTOMICROGRAPH OF ZIRCONIUM SPECIMEN AFTER REACTION WITH OXYGEN AT $900 \mathrm{C}$ FOR 418 MINUTES

(Polarized Light)

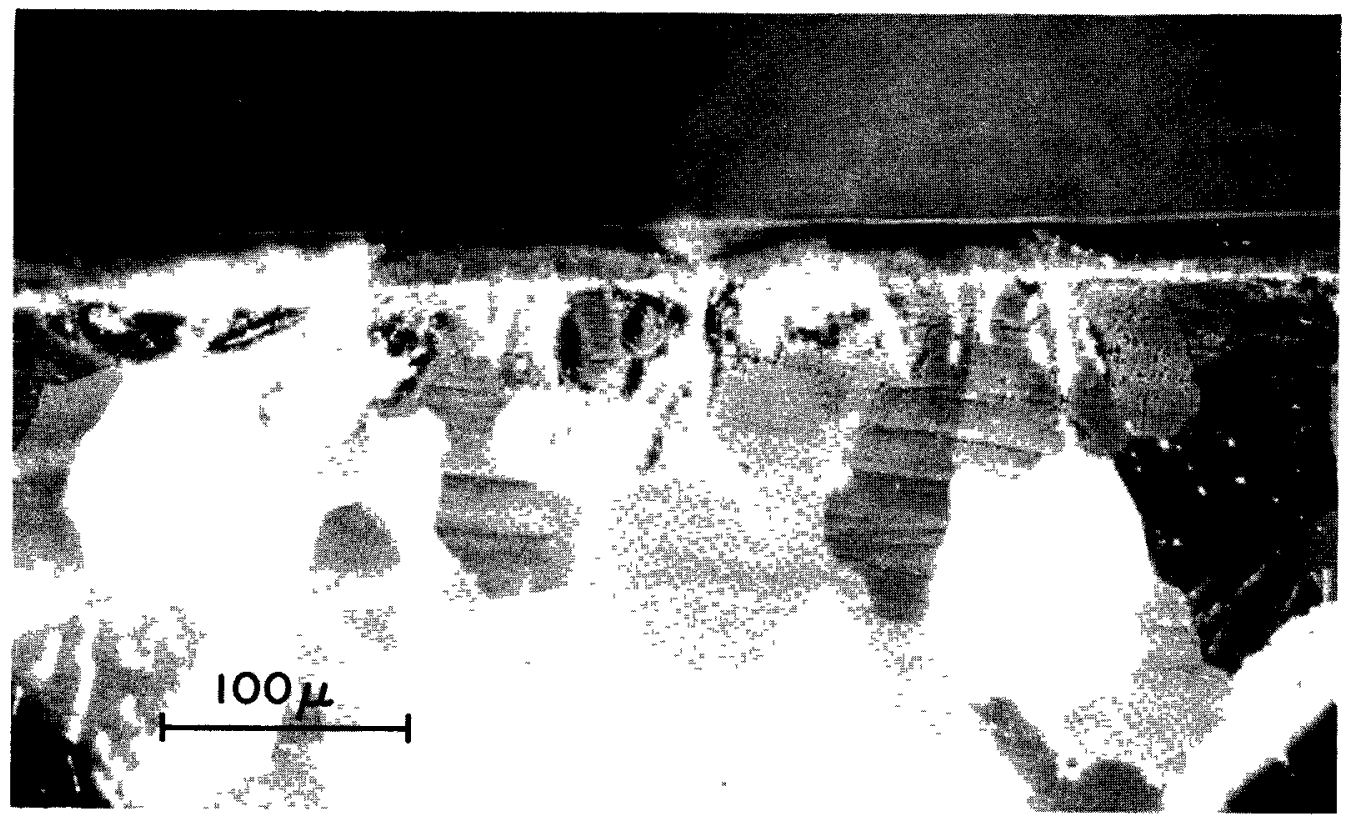


D. Effect of Pressure

The effect of variation in pressure on the reaction rate kinetics was determined. Runs were made at oxygen pressures of 50,200 , and $800 \mathrm{~mm}$ in temperature range from 400 to $900 \mathrm{C}$. At 400 and $500 \mathrm{C}$, no runs were made at $800 \mathrm{~mm}$, since the apparatus was relatively insensitive to the slow rates of oxidation encountered at the se temperatures. The averaged data presented in Table $\mathrm{V}$ show that the oxidation rate is relatively insensitive to pressure. The values of the log-log slopes indicated the cubic rate law at all pressures. The cubic rate constants agreed very well at the different pressures and no apparent trend could be seen at any temperature. These results confirm the work of other investigators who found no pressure effect.

TABLE V

\begin{tabular}{|c|c|c|c|}
\hline \multirow[b]{2}{*}{$\begin{array}{l}\text { Temperature } \\
\text { (C) }\end{array}$} & \multicolumn{2}{|c|}{$\frac{\text { Effect of Pressure on the Reac }}{\text { of Zirconium with Oxygen }}$} & \multirow[b]{2}{*}{$\begin{array}{c}\text { Cubic Rate } \\
\text { Constant, } \mathrm{k} \\
{\left[(\mu \mathrm{g} / \mathrm{sq} \mathrm{cm})^{3} / \mathrm{min}\right]}\end{array}$} \\
\hline & $\begin{array}{l}\text { Oxygen } \\
\text { Pressure } \\
(\mathrm{mm})\end{array}$ & $\begin{array}{l}\text { Slope of } \\
\text { Log-Log } \\
\text { Plot }(1 / n)\end{array}$ & \\
\hline 400 & 50 & $0.32 \pm 0.03$ & $(12 \pm 6.8) \times 10^{2}$ \\
\hline 400 & 200 & $0.29 \pm 0.00$ & $(11 \pm 5.2) \times 10^{2}$ \\
\hline 500 & 50 & $0.31 \pm 0.01$ & $(2.6 \pm 0.1) \times 10^{4}$ \\
\hline 500 & 200 & $0.31 \pm 0.01$ & $(3.5 \pm 0.1) \times 10^{4}$ \\
\hline 600 & 50 & $0.31 \pm 0.01$ & $(6.0 \pm 0.8) \times 10^{5}$ \\
\hline 600 & 200 & $0.33 \pm 0.01$ & $(1.2 \pm 0.4) \times 10^{6}$ \\
\hline 600 & 800 & $0.32 \pm 0.00$ & $(1.0 \pm 0.1) \times 10^{6}$ \\
\hline 700 & 50 & $0.32 \pm 0.05$ & $(1.4 \pm 0.1) \times 10^{7}$ \\
\hline 700 & 200 & $0.34 \pm 0.02$ & $(1.6 \pm 0.2) \times 10^{7}$ \\
\hline 700 & 800 & $0.34 \pm 0.02$ & $(1.8 \pm 0.2) \times 10^{7}$ \\
\hline 800 & 50 & $0.34 \pm 0.01$ & $(1.1 \pm 0.0) \times 10^{8}$ \\
\hline 800 & 200 & $0.37 \pm 0.01$ & $(1.3 \pm 0.0) \times 10^{8}$ \\
\hline 800 & 800 & $0.31 \pm 0.06$ & $(1.3 \pm 0.2) \times 10^{8}$ \\
\hline 900 & 50 & $0.36 \pm 0.01$ & $(7.6 \pm 1.2) \times 10^{8}$ \\
\hline 900 & 200 & $0.33 \pm 0.01$ & $(5.3 \pm 0.0) \times 10^{8}$ \\
\hline 900 & 800 & $0.35 \pm 0.02$ & $(6.0 \pm 1.6) \times 10^{8}$ \\
\hline
\end{tabular}

E. Effect of Additives to Zirconium

The study of the effect of small amounts of impurities on the oxidation kinetics of zirconium was carried out using the series of binary zirconium alloys described earlier. These were alloys of zirconium with aluminum, beryllium, carbon, chromium, cobalt, copper, hafnium, iron, lead, molybdenum, nickel, niobium, platinum, silicon, tantalum, tin, titanium, tungsten, uranium, and vanadium. Each binary system included three nominal compositions - 1, 2, and 4 atom per cent - except that the four atom per cent tungsten alloy was impossible to fabricate.

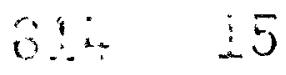


The experimental conditions used were $700 \mathrm{C}$ and $200 \mathrm{~mm}$ of oxygen. The choice of a particular temperature and pressure was somewhat arbitrary, but was dictated by certain important considerations. It was desirable to work at some high temperature in the alpha-zirconium region, so that the oxidation would take place at a conveniently measurable rate at reasonable pressures. This limited the temperature range from approximately $600 \mathrm{C}$ to the alpha-to-beta transformation temperature, $862 \mathrm{C}$. Certain metals, e.g., cobalt, copper, chromium, iron, molybdenum, nickel, niobium, platinum, tantalum, titanium, tungsten, uranium, and vanadium, could be expected to lower the transformation temperature. (18) Therefore, it was decided to work at $700 \mathrm{C}$, which was far enough below $862 \mathrm{C}$ to be sure that beta zirconium was not present in any of the alloys. Another factor in favor of choosing $700 \mathrm{C}$ as the temperature at which to make the study was that in a recent study $(8)$ on the high-temperature oxidation of two zirconium-tin alloys it was reported that the minimum times for breakdown of the protective properties of the films occurred at $700 \mathrm{C}$.

The kinetic data for the oxidation of the alloys were measured and compared with those of pure zirconium. In most cases duplicate runs were made with each alloy composition and the results averaged. While a number of the alloys showed a behavior similar to that of pure zirconium, certain ones, such as those containing tin, were found to behave quite differently. The runs started by following the usual cubic rate law, i.e., an initial rapid reaction took place and, as the oxidation continued, the rate of reaction decreased. But after a period of time a transition (breakaway) to an accelerating oxidation occurred. The accelerating oxidation continued for a short while and then leveled off to an essentially linear rate.

The breakaway phenomenon is a general characteristic of the hightemperature corrosion and

\section{Figure 6}

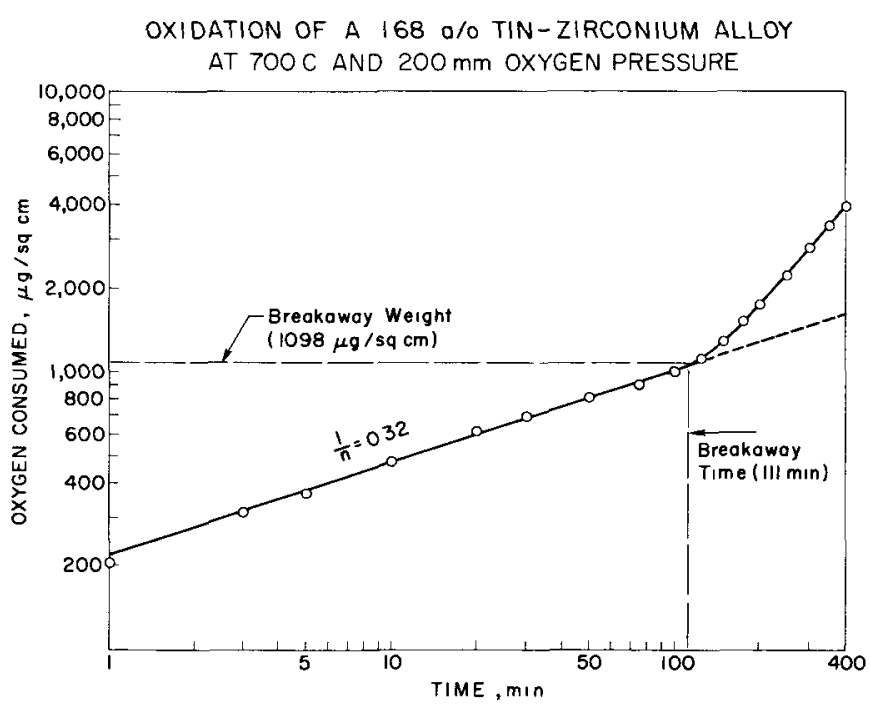

oxidation of zirconium. It has been observed to occur in hightemperature water, (19) in air, $(6,13,14)$ and in oxygen. $(6,8,9)$

When the data were plotted in the usual fashion, log oxygen consumed versus $\log$ time, it was found that after the initial straight line portion of the plot, an upward curvature, which eventually leveled off into another straight line portion, took place. A representative curve of this type is illustrated by the oxidation of the 1.68 atom per cent tin alloy (Figure 6). The "breakaway

$$
\text { ont } 16
$$


time" and "breakaway weight" are defined as the time and oxygen consumed at the last point on the initial straight line portion of the oxidation curve. The sharpness of the breakaway oxidation in the different tin alloys is illustrated in Figure 7. For comparison the data from a run on pure zirconium are included in this figure. It can be seen that the breakaway weight decreased with increasing tin content and also that the slope of the curve after the breakaway is steeper for the 3.60 atom per cent tin alloy than for the other tin alloys.

\section{Figure 7}

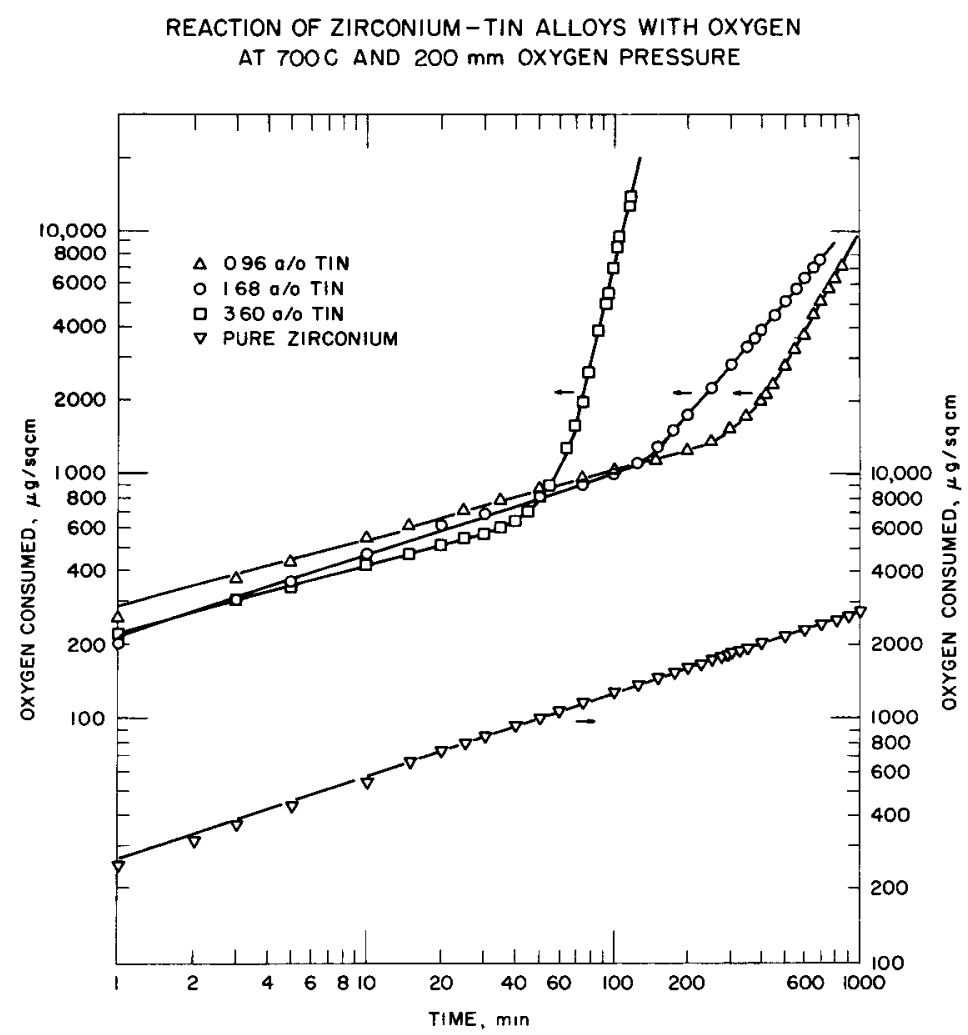

An examination of the results obtained for the various alloys in the series revealed that the alloys fall into four groups, each representing a different type of reaction behavior:

Group I - those alloys which oxidized according to the cubic rate law and did not exhibit breakaway oxidation phenomena;

Group II - those alloys which oxidized according to the parabolic rate law and did not exhibit breakaway oxidation phenomena;

Group III - those alloys which oxidized initially according to the cubic rate law but later exhibited breakaway oxidation phenomena; and

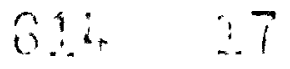


Group IV - those alloys which oxidized initially according to the parabolic rate law but later exhibited breakaway oxidation phenomena.

Figure 8

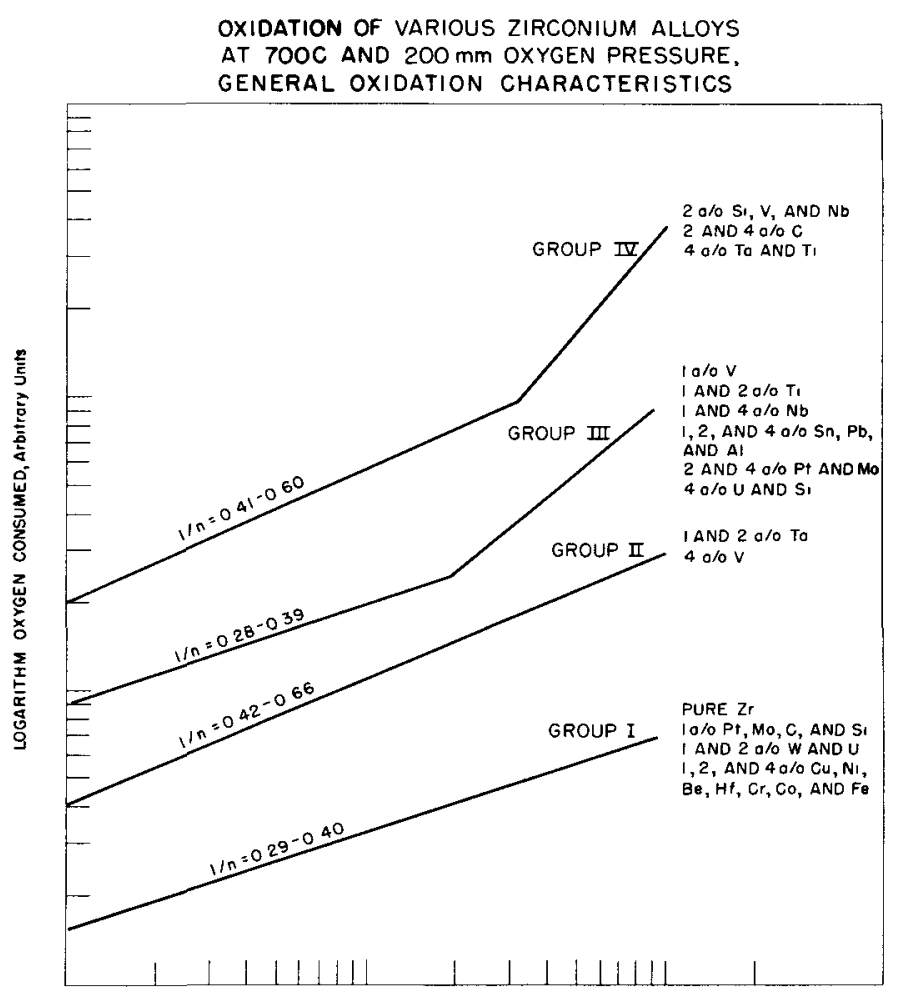

LOGARITHM TIME, Arbitrory Units
The general characteristics of oxidation of the alloys are indicated in Figure 8, which illustrates the four different modes of reaction behavior. The initial rate, breakaway, and total weight gain data are presented in Tables VI and VII. Table VI summarizes the data for alloy systems in which no breakaway was observed at any concentration studied, while Table VII presents the data for alloy systems in which breakaway was observed in at least one concentration.

Many of the alloys and pure zirconium (Group I, Figure 8) showed no breakaway phenomena and oxidized for as long as 1400 minutes according to the cubic rate law, having slopes of log weight gain versus log time plots in the range from 0.28 to 0.40 . The cubic rate constants ranged from $0.78 \times 10^{7}$ to $3.5 \times 10^{7}$ $(\mu \mathrm{g} \text { per sq cm })^{3}$ per min.

The one and two atom per cent tantalum and the four atom per cent vanadium alloys (Group II, Figure 8) showed no breakaway phenomena up to 500 minutes and oxidized according to the parabolic rate law, having loglog slopes in the range from 0.41 to 0.66 . The parabolic rate constants were $39.5 \times 10^{4}, 30.5 \times 10^{4}$, and $29.0 \times 10^{4}(\mu \mathrm{g} \text { per sq } \mathrm{cm})^{2}$ per min, respectively.

Another large group of alloys (Group III, Figure 8) showed breakaway phenomena after oxidizing initially according to the cubic rate law. The cubic rate constants ranged from $0.81 \times 10^{7}$ to $251 \times 10^{7}$ ( $\mu$ g per sq cm) ${ }^{3}$ per min. Breakaway times ranged from 6 to 655 minutes, and breakaway weights ranged from 439 to $9468 \mu \mathrm{g}$ per sq cm. After the breakaways, faster linear rates, ranging from 1.7 to $292 \mu \mathrm{g}$ per sq cm per min, were followed for the duration of the runs. 
TABLE VI

Oxidation of Zirconium Alloys Which Follow the Cubic Rate Law With No Breakaway

$$
\text { (700 C and } 200 \mathrm{~mm} \text { Oxygen) }
$$

\begin{tabular}{|c|c|c|c|c|c|}
\hline $\begin{array}{c}\text { Alloy } \\
\text { Composition } \\
\text { (Atom Per Cent) } \\
\end{array}$ & $\begin{array}{c}\text { Slope of } \\
\text { Log-Log Plot } \\
(1 / n) \\
\end{array}$ & $\begin{array}{l}\text { Cubic Rate Constant } \\
{\left[(\mu \mathrm{g} / \mathrm{sq} \mathrm{cm})^{3} / \mathrm{min} \times 10^{-7}\right]}\end{array}$ & $\begin{array}{l}\text { Length } \\
\text { of Run } \\
(\mathrm{min}) \\
\end{array}$ & $\begin{array}{c}\text { Total } \\
\text { Weight } \\
\text { Gain } \\
(\mu \mathrm{g} / \mathrm{sq} \mathrm{cm}) \\
\end{array}$ & Color and Character of Oxide Film \\
\hline Pure Zr & 0.33 & 1.6 & 1400 & 2845 & Blue-gray; adherent \\
\hline $\begin{array}{l}1.08 \mathrm{Cu} \\
1.84 \mathrm{Cu} \\
3.60 \mathrm{Cu}\end{array}$ & $\begin{array}{l}0.34 \\
0.33 \\
0.33\end{array}$ & $\begin{array}{l}1.1 \\
0.90 \\
0.78\end{array}$ & $\begin{array}{l}1400 \\
1400 \\
1400\end{array}$ & $\begin{array}{l}2458 \\
2347 \\
2385\end{array}$ & $\begin{array}{l}\text { Bl ack; adherent } \\
\text { Black; adherent } \\
\text { Bl ack; adherent }\end{array}$ \\
\hline $\begin{array}{l}0.91 \mathrm{Ni} \\
2.48 \mathrm{Ni} \\
4.22 \mathrm{Ni}\end{array}$ & $\begin{array}{l}0.35 \\
0.34 \\
0.32\end{array}$ & $\begin{array}{l}1.5 \\
1.1 \\
1.0\end{array}$ & $\begin{array}{l}1400 \\
1400 \\
1400\end{array}$ & $\begin{array}{l}2715 \\
2484 \\
2436\end{array}$ & $\begin{array}{l}\text { Black; adherent } \\
\text { Bl ack; adherent } \\
\text { Gray (gold tinge); adherent }\end{array}$ \\
\hline $\begin{array}{l}0.90 \mathrm{Be} \\
2.09 \mathrm{Be} \\
4.23 \mathrm{Be}\end{array}$ & $\begin{array}{l}0.29 \\
0.34 \\
0.30\end{array}$ & $\begin{array}{l}1.2 \\
1.3 \\
1.1\end{array}$ & $\begin{array}{l}1400 \\
1400 \\
1400\end{array}$ & $\begin{array}{l}2513 \\
2542 \\
2400\end{array}$ & $\begin{array}{l}\text { Blue (gold tinge); adherent } \\
\text { Black (blue tinge); adherent } \\
\text { Black with white raised edges; adherent }\end{array}$ \\
\hline $\begin{array}{l}1.03 \mathrm{Hf} \\
2.22 \mathrm{Hf} \\
4.08 \mathrm{Hf}\end{array}$ & $\begin{array}{l}0.34 \\
0.34 \\
0.35\end{array}$ & $\begin{array}{l}1.4 \\
1.4 \\
1.4\end{array}$ & $\begin{array}{l}1400 \\
1400 \\
1400\end{array}$ & $\begin{array}{l}2673 \\
2648 \\
2529\end{array}$ & $\begin{array}{l}\text { Black with raised edges; adherent } \\
\text { Gray-black with raised edges; adherent } \\
\text { Black with raised edges; adherent }\end{array}$ \\
\hline $\begin{array}{l}0.77 \mathrm{Cr} \\
1.63 \mathrm{Cr} \\
3.61 \mathrm{Cr}\end{array}$ & $\begin{array}{l}0.33 \\
0.34 \\
0.33\end{array}$ & $\begin{array}{l}1.7 \\
1.9 \\
1.7\end{array}$ & $\begin{array}{l}1400 \\
1400 \\
1400\end{array}$ & $\begin{array}{l}2850 \\
2987 \\
2923\end{array}$ & $\begin{array}{l}\text { Bl ack; adherent } \\
\text { Bl ue-gray; adherent } \\
\text { Black; adherent }\end{array}$ \\
\hline $\begin{array}{l}0.86 \text { Co } \\
2.49 \text { Co } \\
3.72 \text { Co }\end{array}$ & $\begin{array}{l}0.34 \\
0.34 \\
0.33\end{array}$ & $\begin{array}{l}1.6 \\
1.7 \\
2.2\end{array}$ & $\begin{array}{l}1285 \\
1400 \\
1400\end{array}$ & $\begin{array}{l}2725 \\
2884 \\
3118\end{array}$ & $\begin{array}{l}\text { Gray-black; adherent } \\
\text { Gray; adherent } \\
\text { Gray (gold tinge); adherent }\end{array}$ \\
\hline $\begin{array}{ll}1.09 & \mathrm{Fe} \\
1.98 & \mathrm{Fe} \\
3.95 & \mathrm{Fe}\end{array}$ & $\begin{array}{l}0.34 \\
0.35 \\
0.33\end{array}$ & $\begin{array}{l}3.0 \\
2.7 \\
2.4\end{array}$ & $\begin{array}{l}1300 \\
1400 \\
1400\end{array}$ & $\begin{array}{l}3400 \\
3335 \\
3200\end{array}$ & $\begin{array}{l}\text { Gold-gray; adherent } \\
\text { Blue-gray; adherent } \\
\text { Grey; adherent }\end{array}$ \\
\hline $\begin{array}{l}0.68 \mathrm{~W} \\
1.96 \mathrm{~W}\end{array}$ & $\begin{array}{l}0.35 \\
0.35\end{array}$ & $\begin{array}{l}1.9 \\
3.5\end{array}$ & $\begin{array}{l}1400 \\
1400\end{array}$ & $\begin{array}{l}2980 \\
3570\end{array}$ & $\begin{array}{l}\mathrm{Bl} \text { ack; adherent } \\
\mathrm{Black} \text { with yellow adherent oxide at } \\
\quad \text { flaws in metal; adherent }\end{array}$ \\
\hline
\end{tabular}


TABLE VII

Oxidation of Zirconium Alloys Which Show Breakaway

\begin{tabular}{|c|c|c|c|}
\hline $\begin{array}{c}\text { Alloy } \\
\text { Composition } \\
\text { (Atom Per Cent) } \\
\end{array}$ & $\begin{array}{c}\text { Slope of } \\
\text { Log-Log } \\
\text { Plot } \\
(1 / n) \\
\end{array}$ & $\begin{array}{c}\text { Rate } \\
\text { Constant } \\
\end{array}$ & $\begin{array}{c}\text { Break away } \\
\text { Time } \\
(\mathrm{mln}) \\
\end{array}$ \\
\hline $\begin{array}{l}1.04 \mathrm{Ta} \\
1.78 \mathrm{Ta} \\
3.54 \mathrm{Ta}\end{array}$ & $\begin{array}{l}0.60 \\
0.66 \\
0.60\end{array}$ & $\begin{array}{ll}\text { p } & 39.5 \\
\text { p } & 30.5 \\
\text { p } & 26.9\end{array}$ & 270 \\
\hline $\begin{array}{l}0.89 \mathrm{U} \\
1.76 \mathrm{U} \\
3.52 \mathrm{U}\end{array}$ & $\begin{array}{l}0.36 \\
0.36 \\
0.35\end{array}$ & $\begin{array}{l}3.2 \\
4.1 \\
3.5\end{array}$ & 530 \\
\hline $\begin{array}{l}1.08 \mathrm{Pt} \\
2.04 \mathrm{Pt} \\
4.22 \mathrm{Pt}\end{array}$ & $\begin{array}{l}0.34 \\
0.32 \\
0.31\end{array}$ & $\begin{array}{l}1.5 \\
0.91 \\
0.81\end{array}$ & $\begin{array}{l}630 \\
655\end{array}$ \\
\hline $\begin{array}{l}1.03 \mathrm{Mo} \\
2.34 \mathrm{Mo} \\
3.65 \mathrm{Mo}\end{array}$ & $\begin{array}{l}0.36 \\
0.35 \\
0.36\end{array}$ & $\begin{array}{l}2.5 \\
7.0 \\
3.5\end{array}$ & $\begin{array}{l}40 \\
64\end{array}$ \\
\hline $\begin{array}{l}0.96 \mathrm{Sn} \\
1.68 \mathrm{Sn} \\
3.60 \mathrm{Sn}\end{array}$ & $\begin{array}{l}0.28 \\
0.32 \\
0.31\end{array}$ & $\begin{array}{l}0.92 \\
1.1 \\
2.2\end{array}$ & $\begin{array}{r}235 \\
111 \\
20\end{array}$ \\
\hline $\begin{array}{l}0.58 \mathrm{~Pb} \\
1.62 \mathrm{~Pb} \\
4.00 \mathrm{~Pb}\end{array}$ & $\begin{array}{l}0.28 \\
0.30 \\
0.28\end{array}$ & $\begin{array}{l}1.1 \\
1.6 \\
0.85\end{array}$ & $\begin{array}{r}273 \\
34 \\
7\end{array}$ \\
\hline $\begin{array}{l}1.42 \mathrm{Al} \\
2.15 \mathrm{Al} \\
3.62 \mathrm{Al}\end{array}$ & $\begin{array}{l}0.36 \\
0.33 \\
0.29\end{array}$ & $\begin{array}{r}14.0 \\
12.0 \\
8.0\end{array}$ & $\begin{array}{r}25 \\
24 \\
7\end{array}$ \\
\hline $\begin{array}{ll}0.80 & \mathrm{~S}_{1} \\
1.94 & \mathrm{S1} \\
3.60 & \mathrm{S1}\end{array}$ & $\begin{array}{l}0.40 \\
0.43 \\
0.39\end{array}$ & $\begin{array}{l}3.4 \\
\mathrm{p} \quad 2.2 \\
1.7\end{array}$ & $\begin{array}{r}115 \\
6\end{array}$ \\
\hline $\begin{array}{l}1.01 \mathrm{~V} \\
1.84 \mathrm{~V} \\
3.88 \mathrm{~V}\end{array}$ & $\begin{array}{l}0.35 \\
0.41 \\
0.42\end{array}$ & $\begin{array}{rr} & 4.5 \\
\mathrm{p} & 4.3 \\
\mathrm{p} & 29.0\end{array}$ & $\begin{array}{l}530 \\
120\end{array}$ \\
\hline $\begin{array}{l}0.65 \mathrm{C} \\
1.64 \mathrm{C} \\
3.72 \mathrm{C}\end{array}$ & $\begin{array}{l}0.36 \\
0.41 \\
0.46\end{array}$ & $\begin{array}{ll} & 2.5 \\
\text { p } & 2.7 \\
\text { p } & 4.8\end{array}$ & $\begin{array}{l}48 \\
23\end{array}$ \\
\hline $\begin{array}{l}0.60 \mathrm{Nb} \\
1.82 \mathrm{Nb} \\
3.82 \mathrm{Nb}\end{array}$ & $\begin{array}{l}0.36 \\
0.46 \\
0.35\end{array}$ & $\begin{array}{l}5.9 \\
\mathrm{p} \quad 6.2 \\
6.7\end{array}$ & $\begin{array}{r}365 \\
500 \\
49\end{array}$ \\
\hline $\begin{array}{l}1.08 \mathrm{~T}_{1} \\
2.12 \mathrm{~T}_{1} \\
4.16 \mathrm{~T} 1\end{array}$ & $\begin{array}{l}0.37 \\
0.39 \\
0.43\end{array}$ & $\begin{array}{r}69.7 \\
251 \\
p \quad 90.8\end{array}$ & $\begin{array}{l}370 \\
385 \\
275\end{array}$ \\
\hline
\end{tabular}

\begin{tabular}{|c|c|c|c|c|}
\hline $\begin{array}{l}\text { Breakaway } \\
\text { Weight } \\
(\mu \mathrm{g} / \mathrm{sq} \mathrm{cm})\end{array}$ & $\begin{array}{l}\text { Breakaway } \\
\text { Rate } \\
{[\mu \mathrm{g} /(\mathrm{sq} \mathrm{cm})(\mathrm{m} \mathbf{n})]}\end{array}$ & $\begin{array}{l}\text { Length } \\
\text { of Run } \\
(\mathrm{m} 1 \mathrm{n})\end{array}$ & $\begin{array}{l}\text { Total } \\
\text { Werght } \\
\text { Gain } \\
(\mu \mathrm{g} / \mathrm{sq} \mathrm{cm}) \\
\end{array}$ & Color and Character of Oxide Film \\
\hline 7830 & 26.1 & $\begin{array}{l}500 \\
500 \\
500\end{array}$ & $\begin{array}{l}13200 \\
11600 \\
13000\end{array}$ & $\begin{array}{l}\text { Blue-black with raised edges, adherent } \\
\text { Black with raised edges, adherent } \\
\text { Silver-white with raised edges, adherent }\end{array}$ \\
\hline 2645 & 1.7 & $\begin{array}{l}1400 \\
1400 \\
1400\end{array}$ & $\begin{array}{l}3535 \\
3938 \\
4078\end{array}$ & $\begin{array}{l}\text { Black with raised edges, } 2 \text { faces gold flaky oxide } \\
\text { Black with raised yellow edges, adherent } \\
\text { Black with rassed yellow edges, adherent }\end{array}$ \\
\hline $\begin{array}{l}1815 \\
1763\end{array}$ & $\begin{array}{l}2.9 \\
1.8\end{array}$ & $\begin{array}{l}1400 \\
1400 \\
1400\end{array}$ & $\begin{array}{l}2684 \\
3225 \\
2980\end{array}$ & $\begin{array}{l}\text { Black, adherent } \\
\text { Black with blisters, adherent } \\
\text { Bl ack with raised edges, adherent }\end{array}$ \\
\hline $\begin{array}{l}1368 \\
1248\end{array}$ & $\begin{array}{l}13.1 \\
11.9\end{array}$ & $\begin{array}{r}1400 \\
850 \\
850\end{array}$ & $\begin{array}{r}3492 \\
10300 \\
10200\end{array}$ & $\begin{array}{l}\text { Black with raised edges and white spots, adherent } \\
\text { Silver-gray with ralsed edges, adherent } \\
\text { Silver-gray with ralsed edges, adherent }\end{array}$ \\
\hline $\begin{array}{r}1345 \\
1098 \\
521\end{array}$ & $\begin{array}{l}12.8 \\
12.9 \\
292\end{array}$ & $\begin{array}{l}650 \\
650 \\
117\end{array}$ & $\begin{array}{r}4450 \\
7100 \\
13071\end{array}$ & $\begin{array}{l}\text { Tan with black spots, adherent } \\
\text { Coral, adherent } \\
\text { White, flakes off }\end{array}$ \\
\hline $\begin{array}{r}1465 \\
835 \\
460\end{array}$ & $\begin{array}{r}9.7 \\
15.9 \\
9.7\end{array}$ & $\begin{array}{l}890 \\
580 \\
895\end{array}$ & $\begin{array}{r}5938 \\
9123 \\
11165\end{array}$ & $\begin{array}{l}\text { Black with raised edges, adherent } \\
\text { Black with ralsed edges, adherent } \\
\text { Silver-gray with ralsed edges, adherent }\end{array}$ \\
\hline $\begin{array}{r}1467 \\
1401 \\
948\end{array}$ & $\begin{array}{l}58.9 \\
49.3 \\
84.2\end{array}$ & $\begin{array}{l}280 \\
280 \\
198\end{array}$ & $\begin{array}{l}14100 \\
13683 \\
16232\end{array}$ & $\begin{array}{l}\text { Ivory with raised edges, adherent } \\
\text { Ivory with rassed edges, adherent } \\
\text { Bl ack, adherent }\end{array}$ \\
\hline $\begin{array}{r}1650 \\
439\end{array}$ & $\begin{array}{l}12.7 \\
97.0\end{array}$ & $\begin{array}{r}1400 \\
600 \\
165\end{array}$ & $\begin{array}{r}3396 \\
5921 \\
12046\end{array}$ & $\begin{array}{l}\text { Gray with white specks on faces, adherent } \\
\text { Tan with rough surface, flakes off } \\
\text { Tan with rough surface, flakes off }\end{array}$ \\
\hline $\begin{array}{l}2810 \\
2363\end{array}$ & $\begin{array}{l}3.9 \\
6.8\end{array}$ & $\begin{array}{r}1285 \\
1175 \\
615\end{array}$ & $\begin{array}{r}5292 \\
9195 \\
14272\end{array}$ & $\begin{array}{l}\text { l face black and } 5 \text { faces yellow and black, adherent } \\
\text { Black wrth rassed edges and yellow-green spots, adherent } \\
\text { Dark yel low wrth rased edges, flakes of }\end{array}$ \\
\hline $\begin{array}{l}1225 \\
1076\end{array}$ & $\begin{array}{l}15.3 \\
25.4\end{array}$ & $\begin{array}{r}1400 \\
600 \\
600\end{array}$ & $\begin{array}{r}3256 \\
7400 \\
17500\end{array}$ & $\begin{array}{l}\text { Silver-gold with white edges and spots, adherent } \\
\text { Gold with rough surface, flakes off } \\
\text { Gray cinder-like oxide, some flakes off }\end{array}$ \\
\hline $\begin{array}{l}2680 \\
5625 \\
1550\end{array}$ & $\begin{array}{r}5.0 \\
7.7 \\
16.3\end{array}$ & $\begin{array}{l}875 \\
875 \\
680\end{array}$ & $\begin{array}{r}5717 \\
8500 \\
10519\end{array}$ & $\begin{array}{l}\text { Black with raised edges, adherent } \\
\text { Silver with raised edges, adherent } \\
\text { Silver-black with ralsed edges, adherent }\end{array}$ \\
\hline $\begin{array}{r}6215 \\
9468 \\
15975\end{array}$ & $\begin{array}{r}9.3 \\
13.0 \\
33.1\end{array}$ & $\begin{array}{l}930 \\
790 \\
590\end{array}$ & $\begin{array}{l}11134 \\
14770 \\
24917\end{array}$ & $\begin{array}{l}\text { Black with raised edges and blisters, adherent } \\
\text { Black with raised edges and blisters, adherent } \\
\text { Black (gold tinge) w1th raised edges, edges flake off, } \\
\text { faces adherent }\end{array}$ \\
\hline
\end{tabular}

aThis term applies only to the portion of run before breakaway.

${ }^{b}$ Cubic rate law constants $\left[10^{7}(\mu \mathrm{g} / \mathrm{sq} \mathrm{cm})^{3} / \mathrm{min}\right]$ unless preceded by p which signifies parabolic rate law constant [10 $\left.4(\mu \mathrm{g} / \mathrm{sq} \mathrm{cm}){ }^{2} / \mathrm{min}\right]$. Both apply only to the portion before breakaway. 
The last group of alloys (Group IV, Figure 8), showed breakaway phenomena after initial parabolic oxidations. The parabolic rate constants ranged from $2.2 \times 10^{4}$ to $90.8 \times 10^{4}(\mu \mathrm{g} \text { per sq } \mathrm{cm})^{2}$ per min. Breakaway times ranged from 23 to 500 minutes, and breakaway weights varied from 1076 to $15,975 \mu \mathrm{g}$ per sq $\mathrm{cm}$. The faster linear rates after breakaways ranged from 6.8 to $33.1 \mu \mathrm{g}$ per sq $\mathrm{cm}$ per min.

The subdivision of alloys into groups is somewhat dangerous since it tends to mask out individual differences that exist. It is only justified on the basis that it provides a convenient method of classifying the oxidation behaviors of the different alloys. In addition, the differences between the groups are partly artificial. It is probable that many of the alloys in Groups I and II would exhibit breakaway phenomena if the runs were carried out for long enough periods of time. Also, in some cases the classification of reaction as cubic or parabolic is somewhat arbitrary, since several alloys had log-log slopes very close to 0.40 (the dividing slope between parabolic and cubic).

Many of the alloys produced oxide films of unusual character. A description of the oxide films formed on each of the alloys studied has been included in Tables VI and VII.

The behaviors of representative alloys of Groups I and II are presented graphically in Figure 9. The plots, linear in the variables, illustrate the usual cubic-type behavior. In a log-log plot straight lines are obtained throughout the length of the runs.

Figure 9

REACTION OF ZIRCONIUM ALLOYS WITH OXYGEN AT 700 C AND $200 \mathrm{~mm}$ OXYGEN PRESSURE

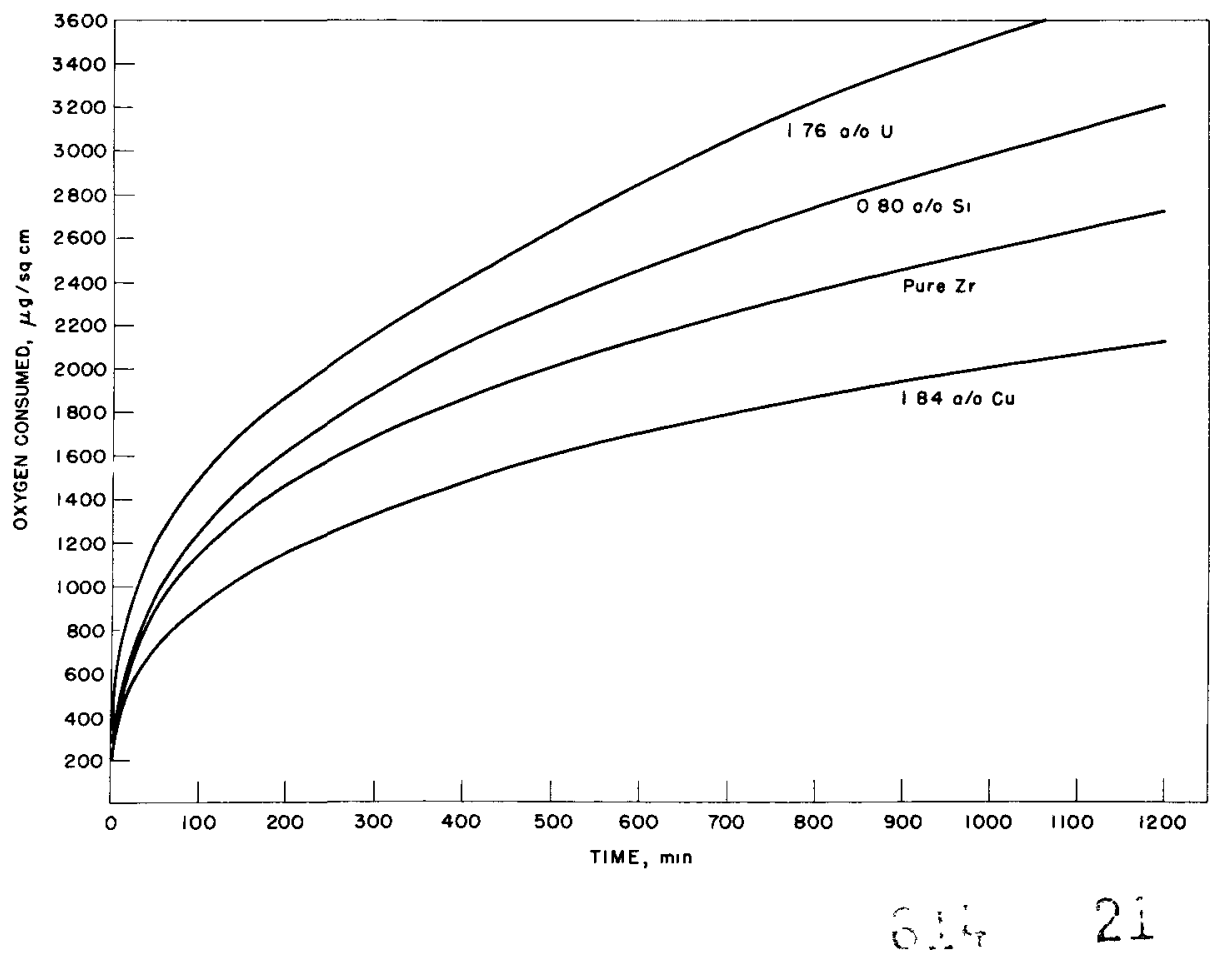


In Figures 10 and 11 are presented data for alloys of Group III, which showed considerably less resistance to oxidation than did pure zirconium.

Figure 10

REACTION OF ZIRCONIUM ALLOYS WITH OXYGEN AT $700 \mathrm{C}$ AND 200 MM OXYGEN PRESSURE

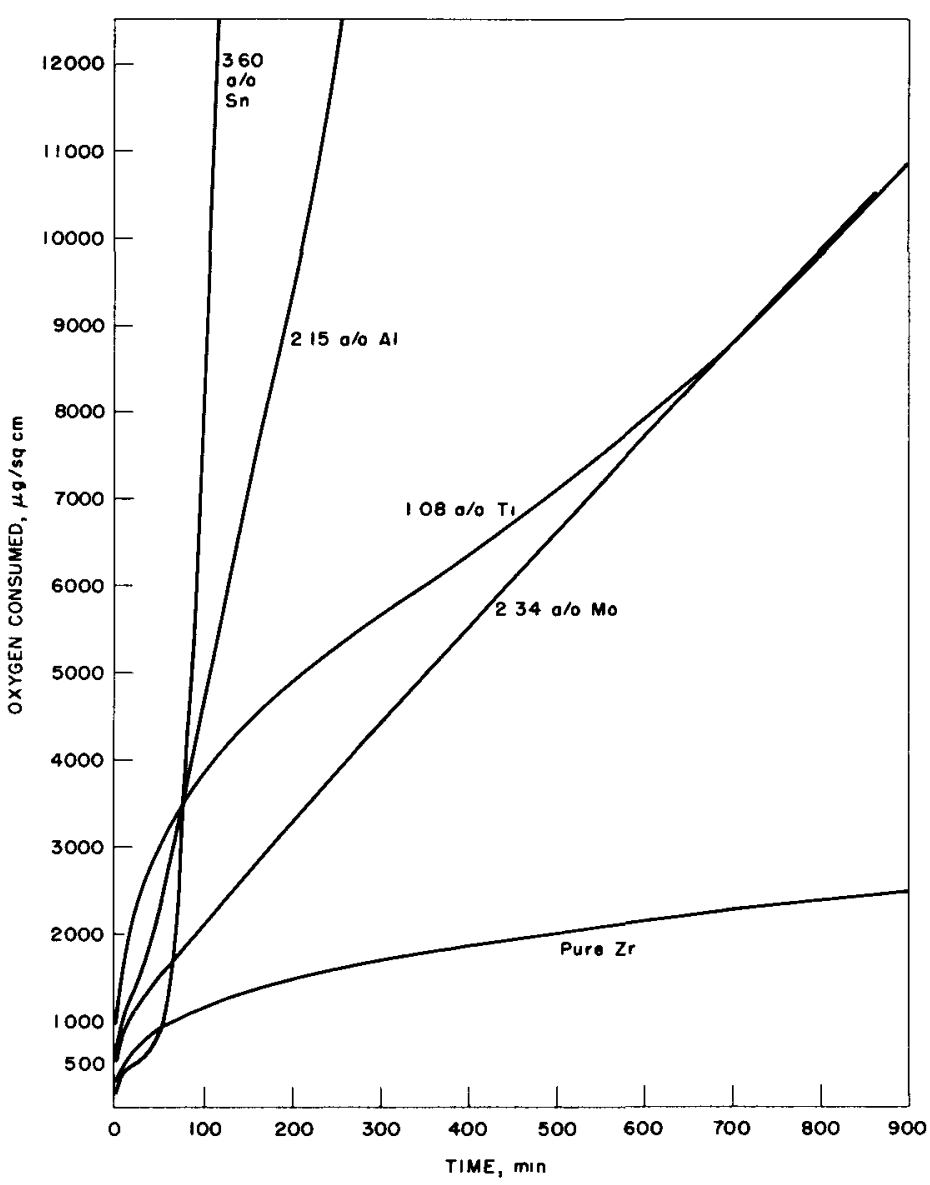

The 3.60 atom per cent tin and 2.15 atom per cent aluminum alloys, in particular, had very short breakaway times and then exhibited extremely fast rates of oxidation after the breakaway. The 1.08 atom per cent titanium showed a very rapid initial rate.

Figure 12 illustrates the oxidation behaviors of some other alloys which exhibited breakaways. The 1.84 atom per cent vanadium alloy followed a nearly parabolic rate before it had a breakaway. The 2.04 atom per cent platinum and the 3.52 atom per cent uranium alloys oxidized for relatively long times before breakaways were observed.

In general, it can be said that most alloys obey the cubic rate law. Even most of those alloys which exhibited a breakaway obeyed the cubic rate law during the initial stages of

the oxidation. Those alloys which do not obey the cubic rate law strictly deviate toward the parabolic rate law.

Tables VI and VII serve to summarize the data in a convenient and compact manner. For a more discerning study of the oxidation characteristics of individual alloys, reference should be made to Figures 13 through 32. Each figure is for a different binary alloy system and illustrates representative runs of the nominal one, two, and four atom per cent concentrations as compared with the behavior of pure zirconium. Among other things, these figures allow a direct comparison of alloys which, on the basis of the log-log slopes, oxidized according to different rate laws. In the zirconiumsilicon system (Figure 28), for example, the one and four atom per cent alloys oxidized in accordance with the cubic rate law, but the two atom per cent alloy was classified as oxidizing according to the parabolic rate. Since direct comparisons of cubic and parabolic rate constants are not possible, figures with the kinetic data are necessary.

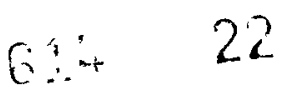


Figure 11

REACTION OF ZIRCONIUM ALLOYS WITH OXYGEN AT $700 \mathrm{C}$ AND $200 \mathrm{~mm}$ OXYGEN PRESSURE

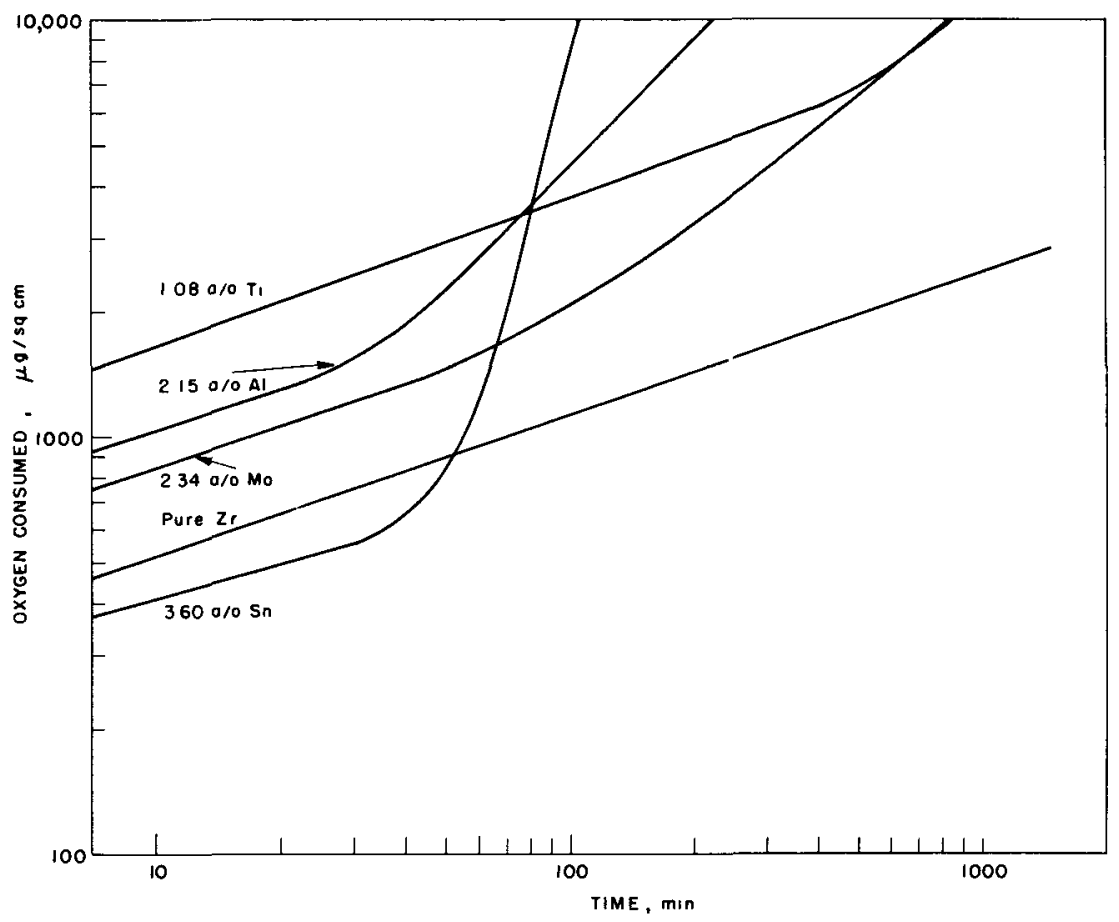

Figure 12

REACTION OF ZIRCONIUM ALLOYS WITH OXYGEN AT TOOC AND $200 \mathrm{~mm}$ OXYGEN PRESSURE

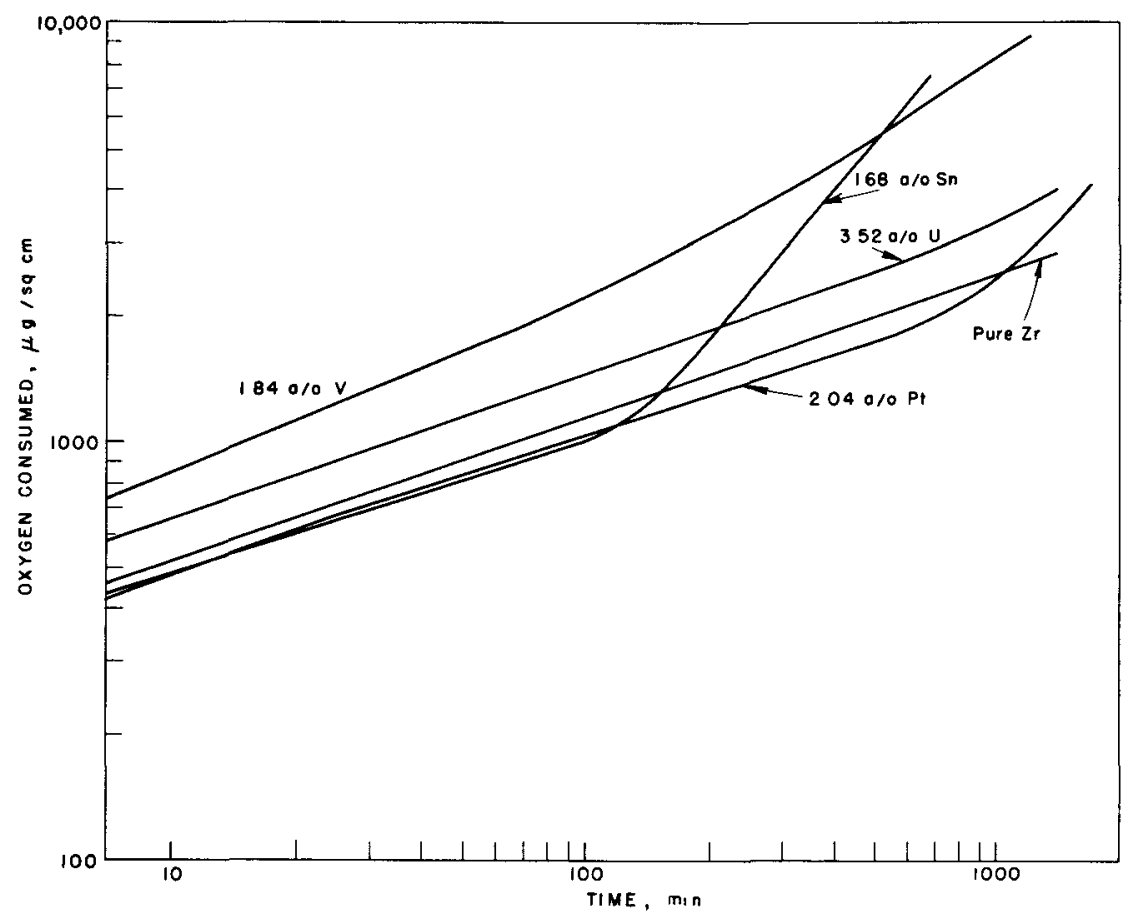

$6 \therefore \quad 23$ 
Figure 13

OXIDATION OF ZIRCONIUM-COPPER ALLOYS AT $700 \mathrm{C}$ IN $200 \mathrm{~mm}$ OXYGEN

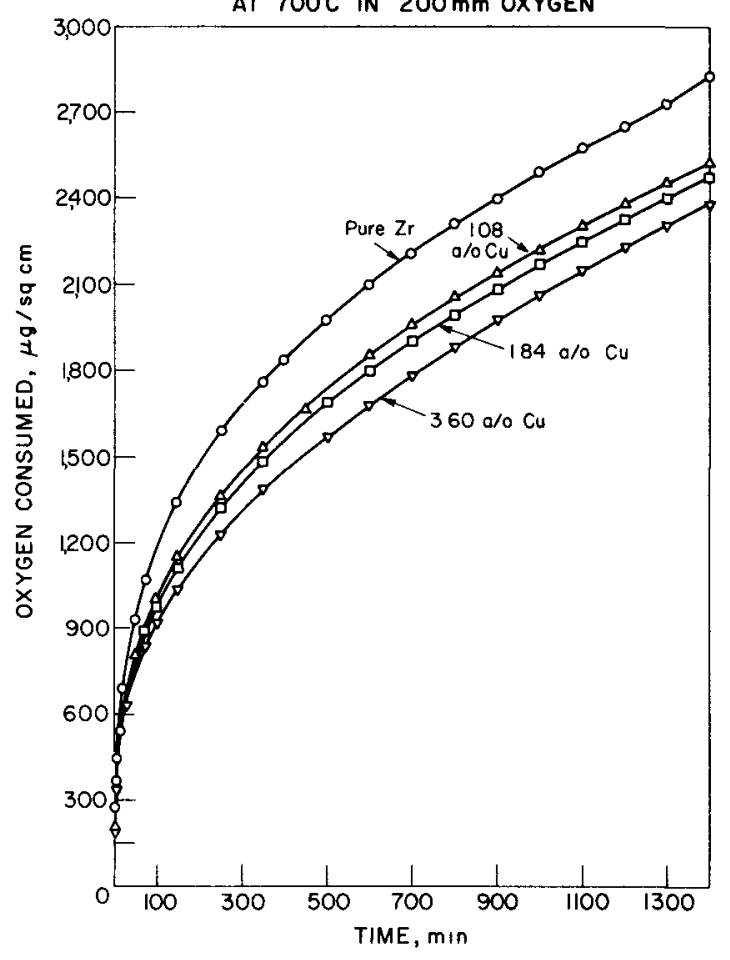

Figure 15

OXIDATION OF ZIRCONIUM-BERYLLIUM ALLOYS AT $700 \mathrm{C} \mathrm{IN} 200 \mathrm{~mm}$ OXYGEN

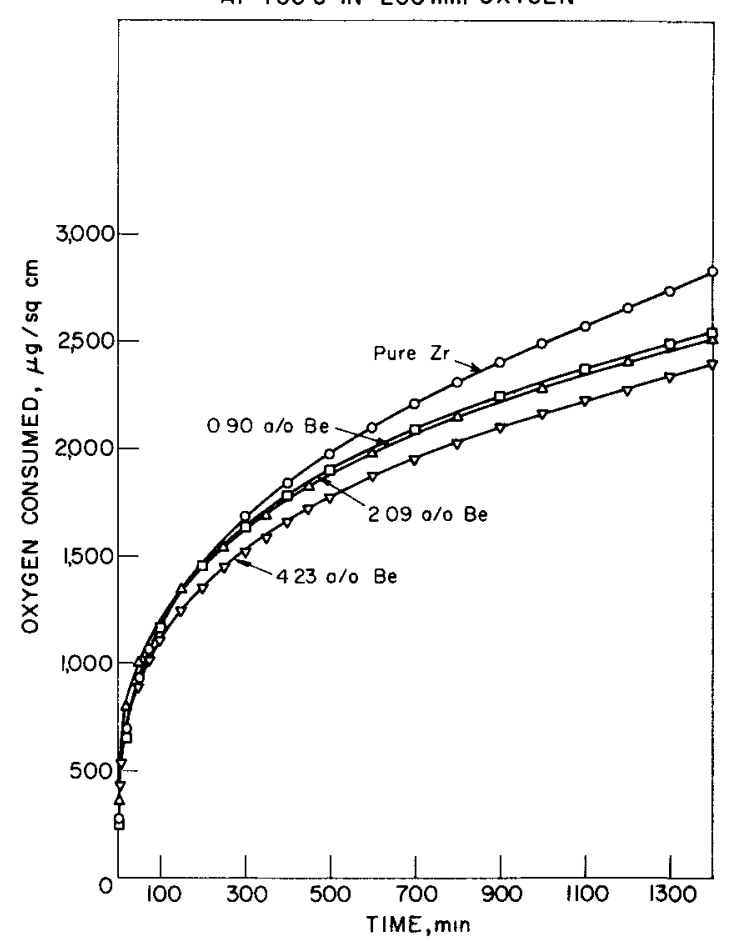

Figure 14

OXIDATION OF ZIRCONIUM-NICKEL ALLOYS AT $700 \mathrm{C}$ IN $200 \mathrm{~mm}$ OXYGEN

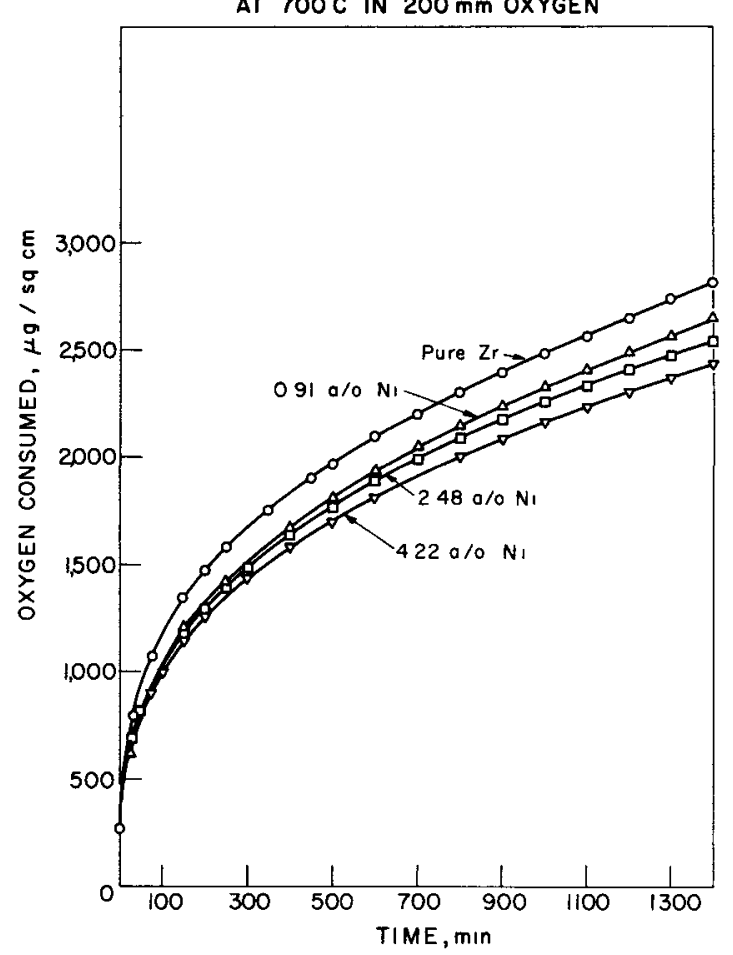

Figure 16

OXIDATION OF ZIRCONIUM-HAFNIUM ALLOYS AT $700 \mathrm{C}$ IN $200 \mathrm{~mm}$ OXYGEN

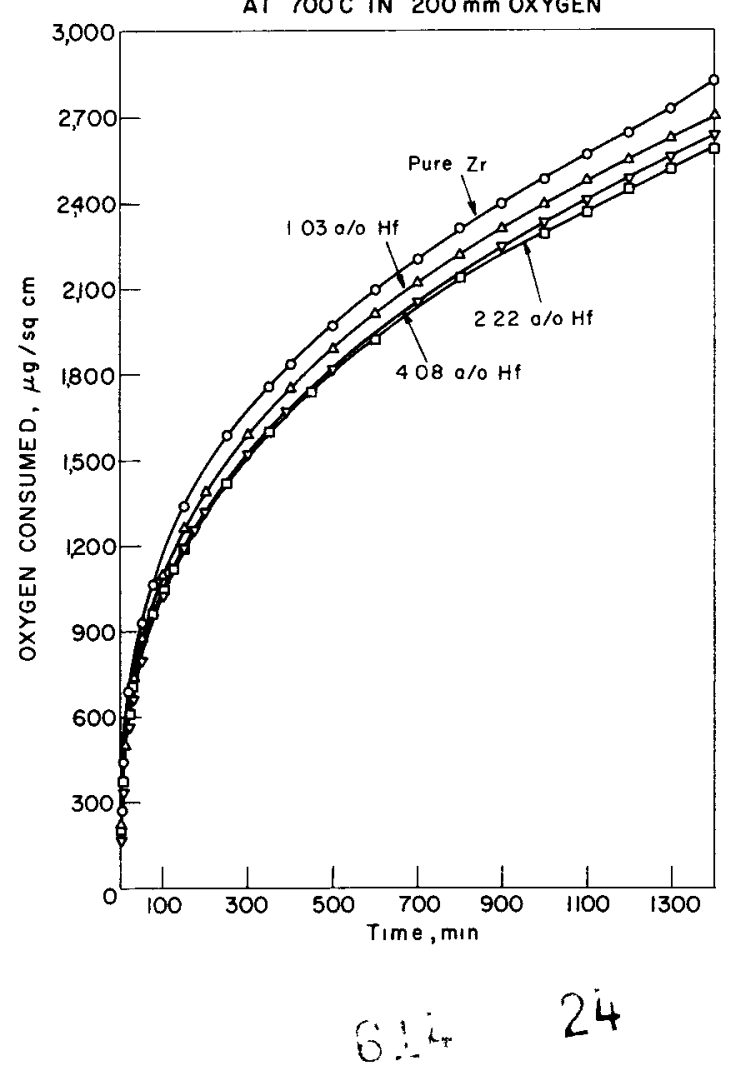


Figure 17

OXIDATION OF ZIRCONIUM-CHROMIUM ALLOYS AT $700 \mathrm{C}$ IN $200 \mathrm{~mm}$ OXYGEN

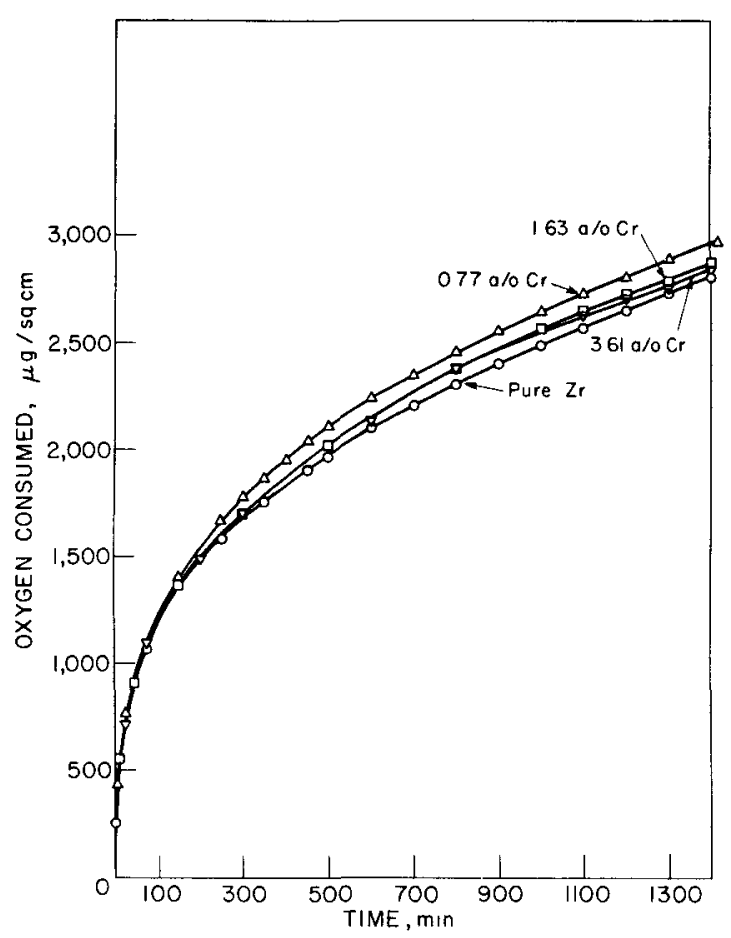

Figure 19

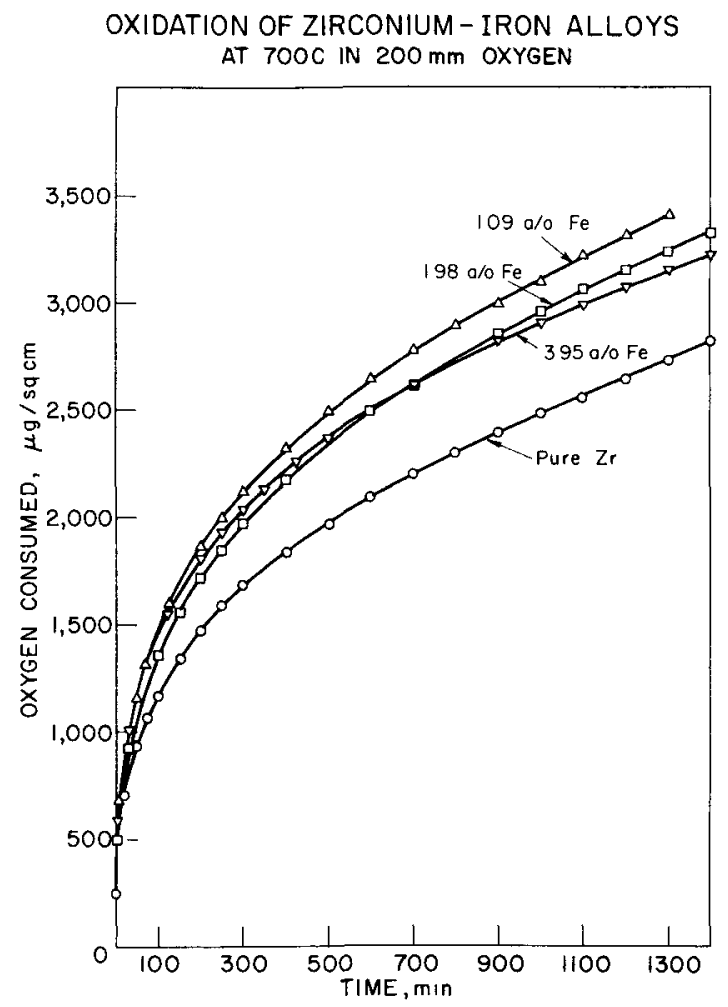

Figure 18

OXIDATION OF ZIRCONIUM - COBALT ALLOYS AT $700 \mathrm{C}$ IN $200 \mathrm{~mm}$ OXYGEN

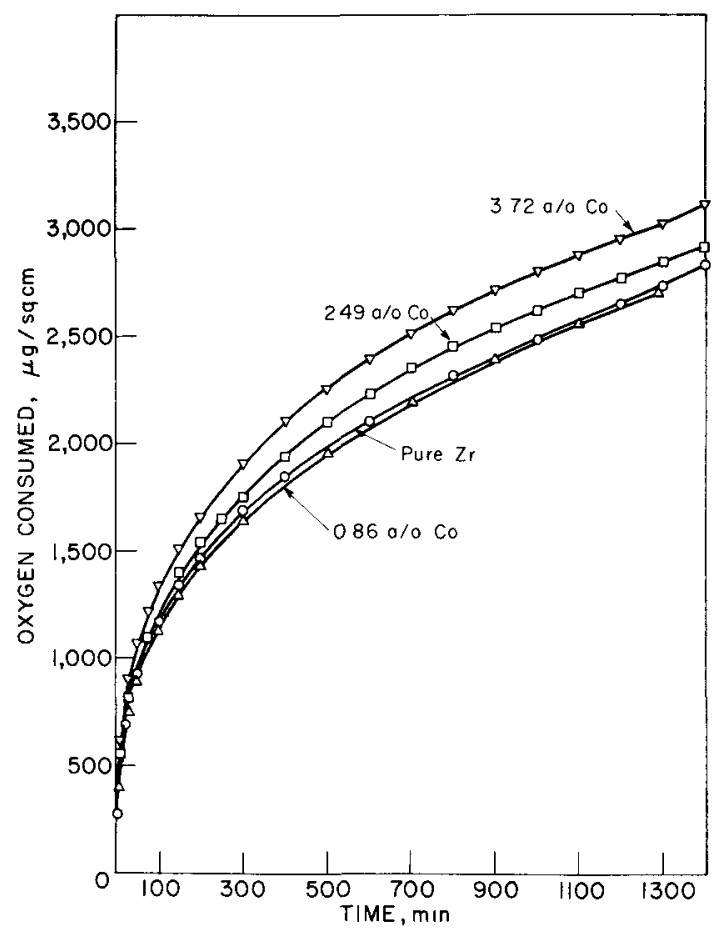

Figure 20

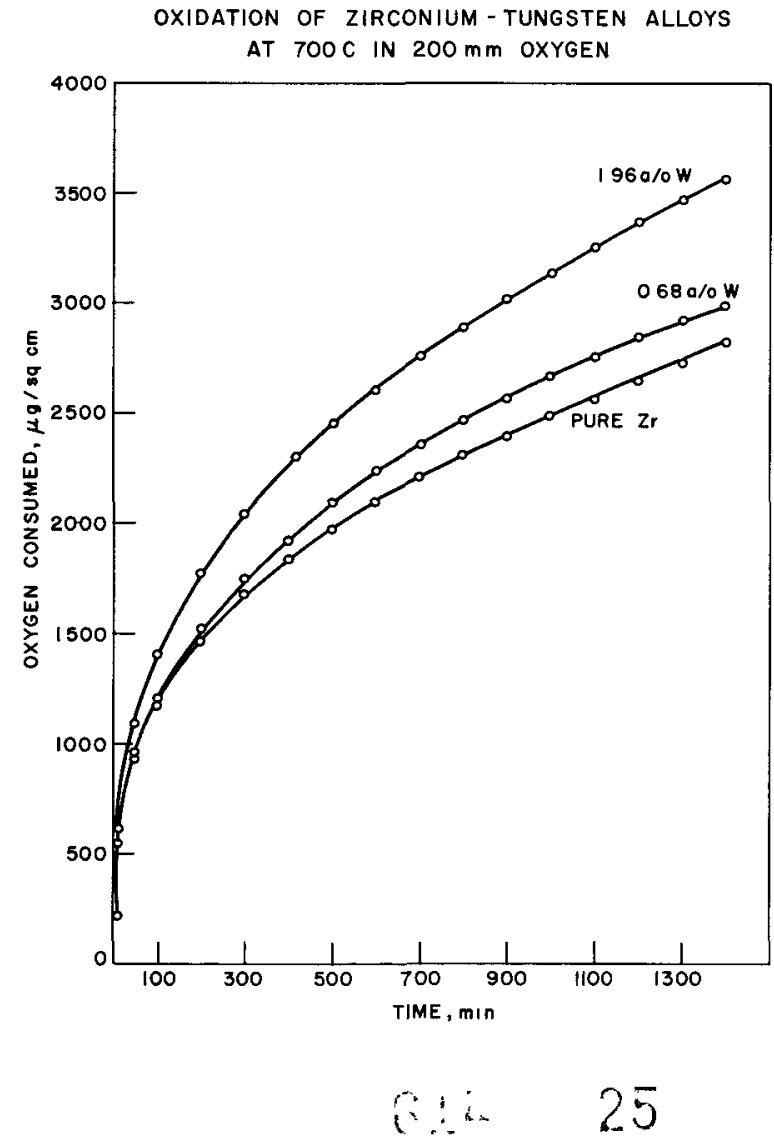


Figure 21

OXIDATION OF ZIRCONIUM-TANTALUM ALLOYS AT $700 \mathrm{C}$ IN $200 \mathrm{~mm}$ OXYGEN

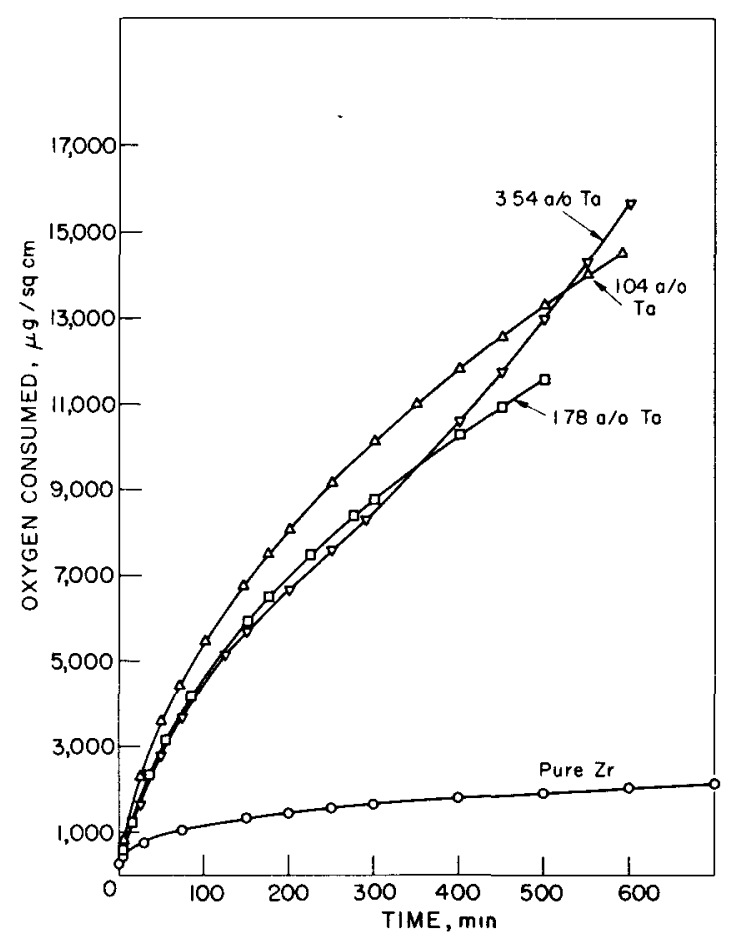

Figure 23

OXIDATION OF ZIRCONIUM-PLATINUM ALLOYS AT $700 \mathrm{C} \mathrm{IN} 200 \mathrm{~mm}$ OXYGEN

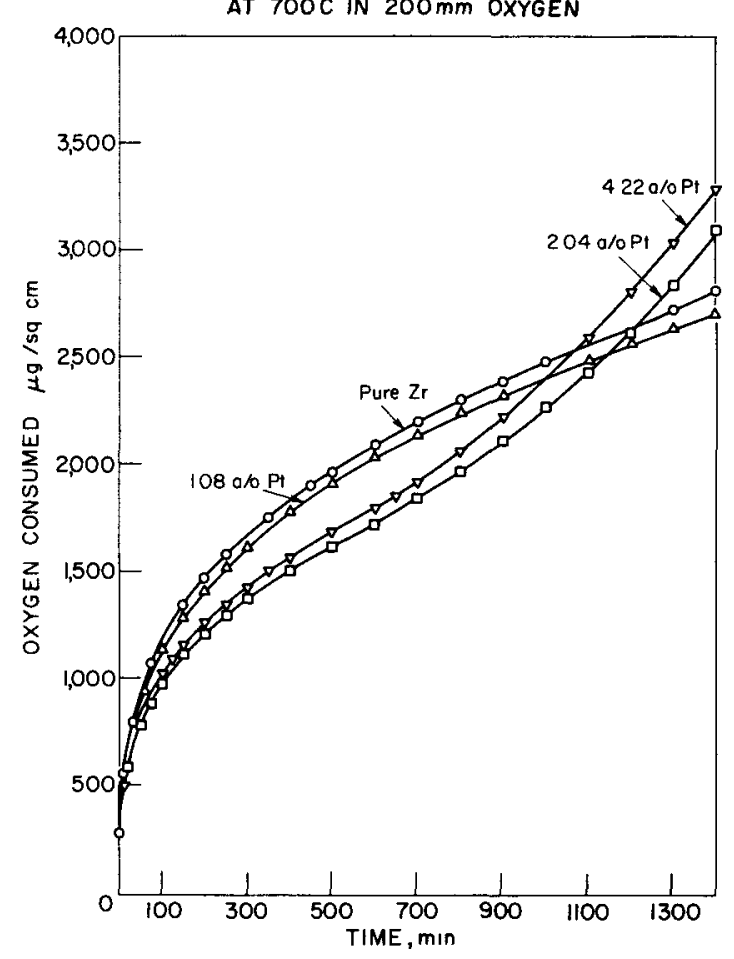

Figure 22

OXIDATION OF ZIRCONIUM-URANIUM ALLOYS AT $700 \mathrm{C}$ IN $200 \mathrm{~mm}$ OXYGEN

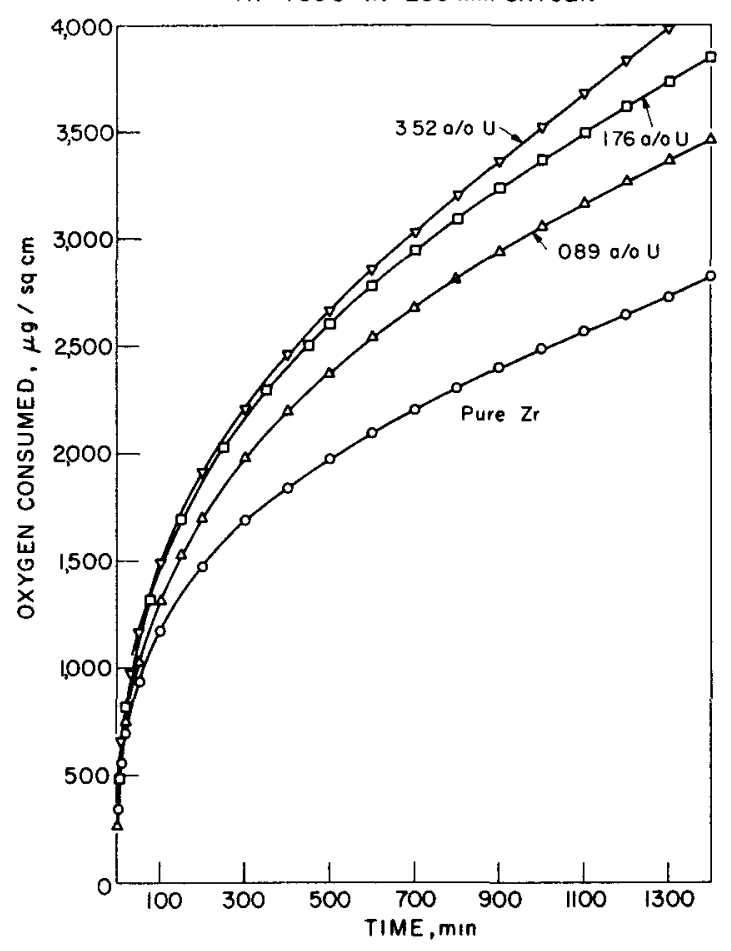

Figure 24

OXIDATION OF ZIRCONIUM-MOLYBDENUM ALLOYS AT $700 \mathrm{C}$ IN $200 \mathrm{~mm}$ OXYGEN

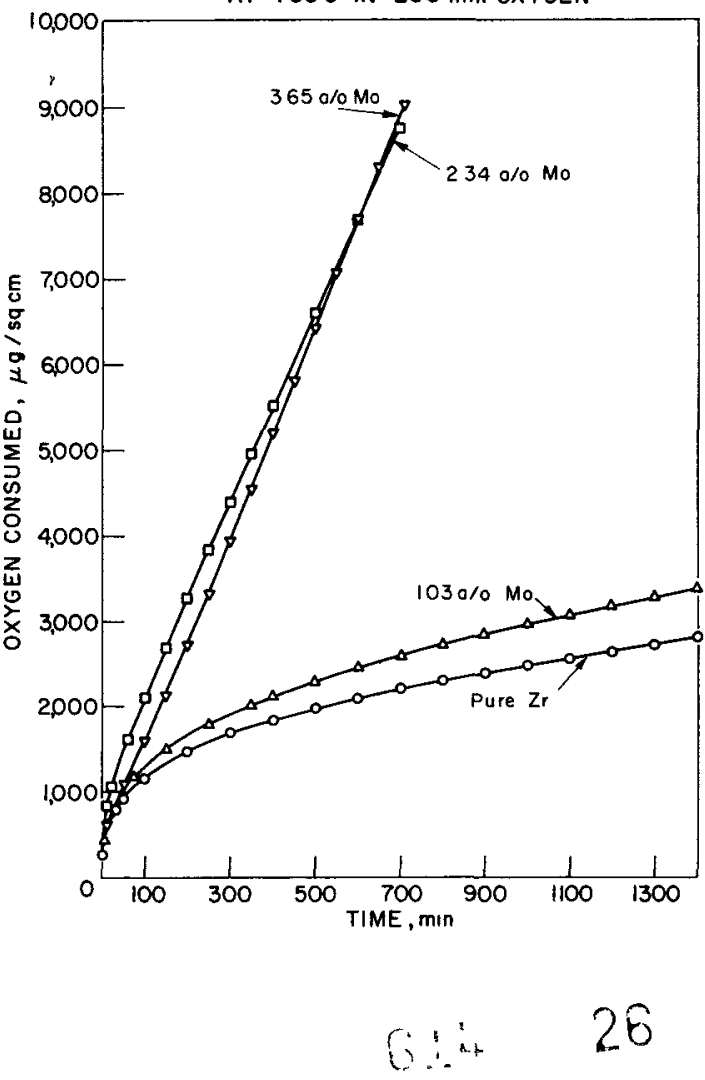


Figure 25

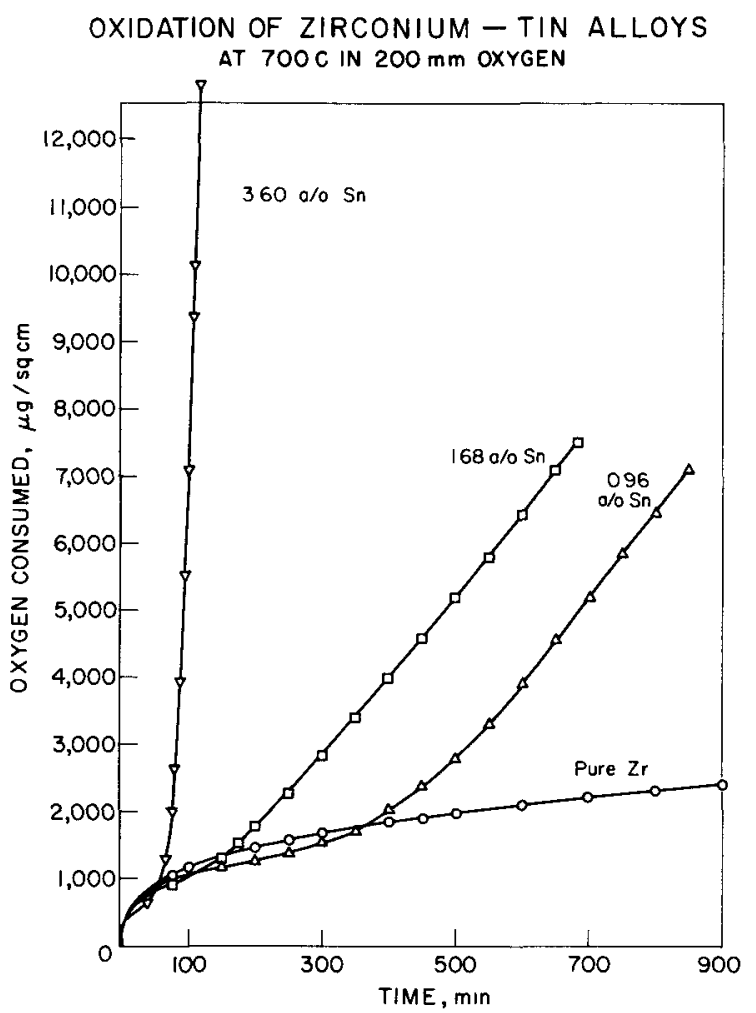

Figure 27

OXIDATION OF ZIRCONIUM-ALUMINUM ALLOYS AT $700 \mathrm{C}$ IN $200 \mathrm{~mm}$ OXYGEN

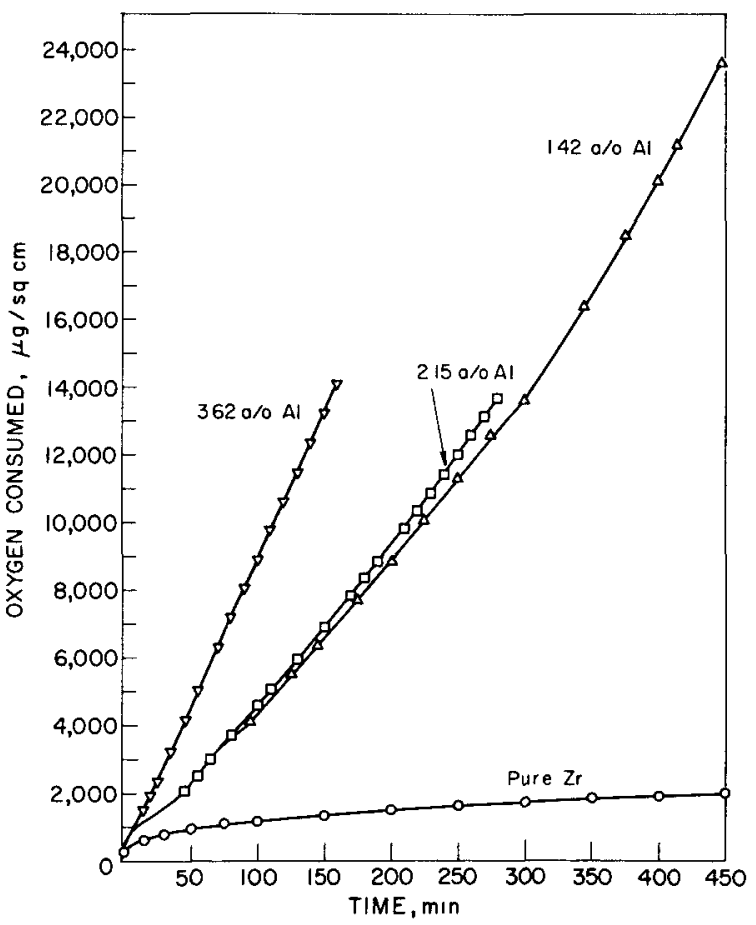

Figure 26

OXIDATION OF ZIRCONIUM - LEAD ALLOYS

AT $700 \mathrm{C}$ IN $200 \mathrm{~mm}$ OXYGEN

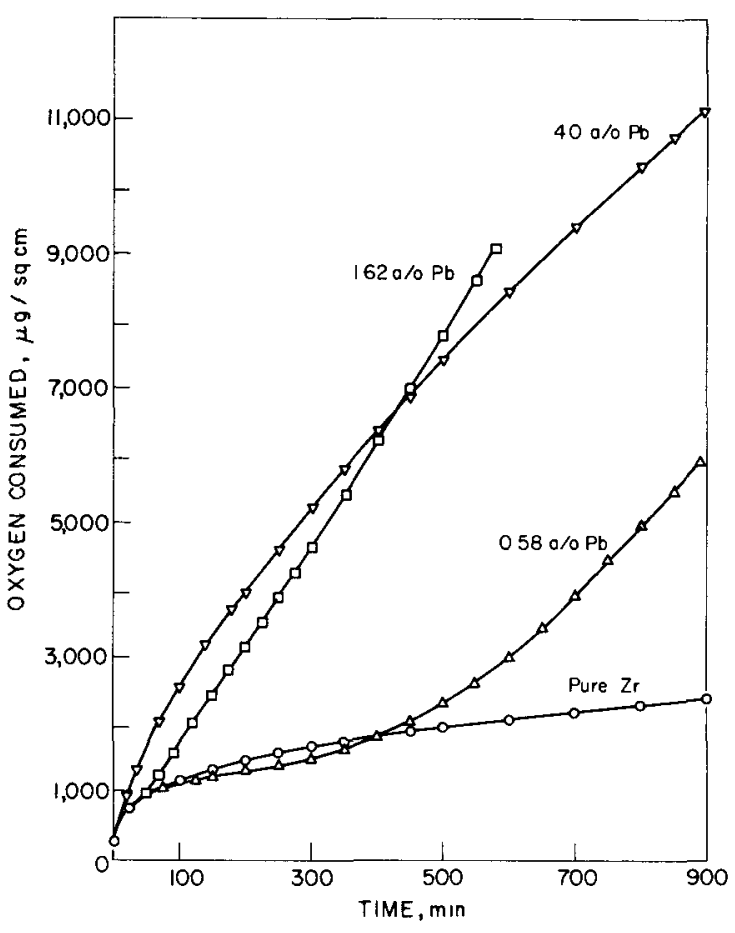

Figure 28

OXIDATION OF ZIRCONIUM-SILICON ALLOYS AT $700 \mathrm{C}$ IN $200 \mathrm{~mm}$ OXYGEN

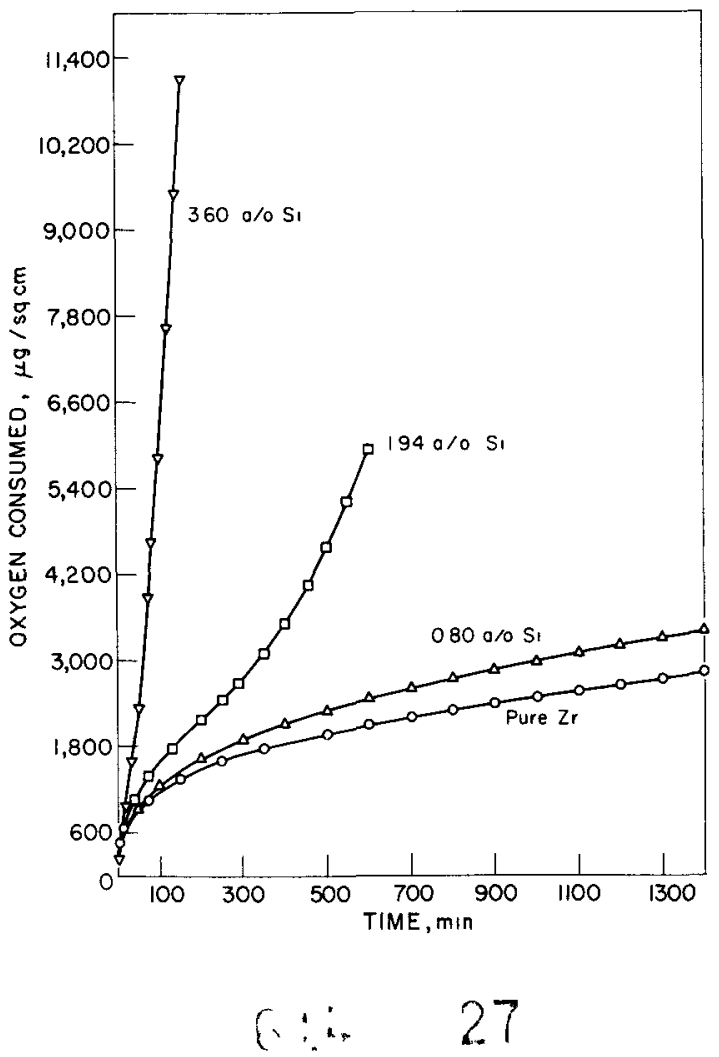


Figure 29

OXIDATION OF ZIRCONIUM - VANADIUM ALLOYS AT $700 \mathrm{C}$ IN $200 \mathrm{~mm}$ OXYGEN

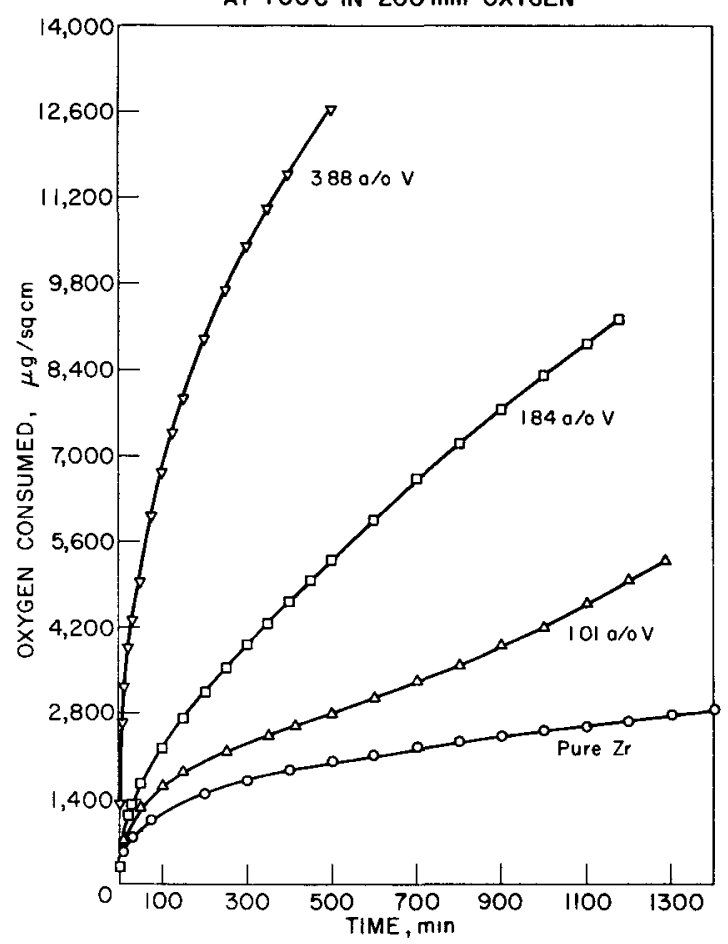

Figure 31

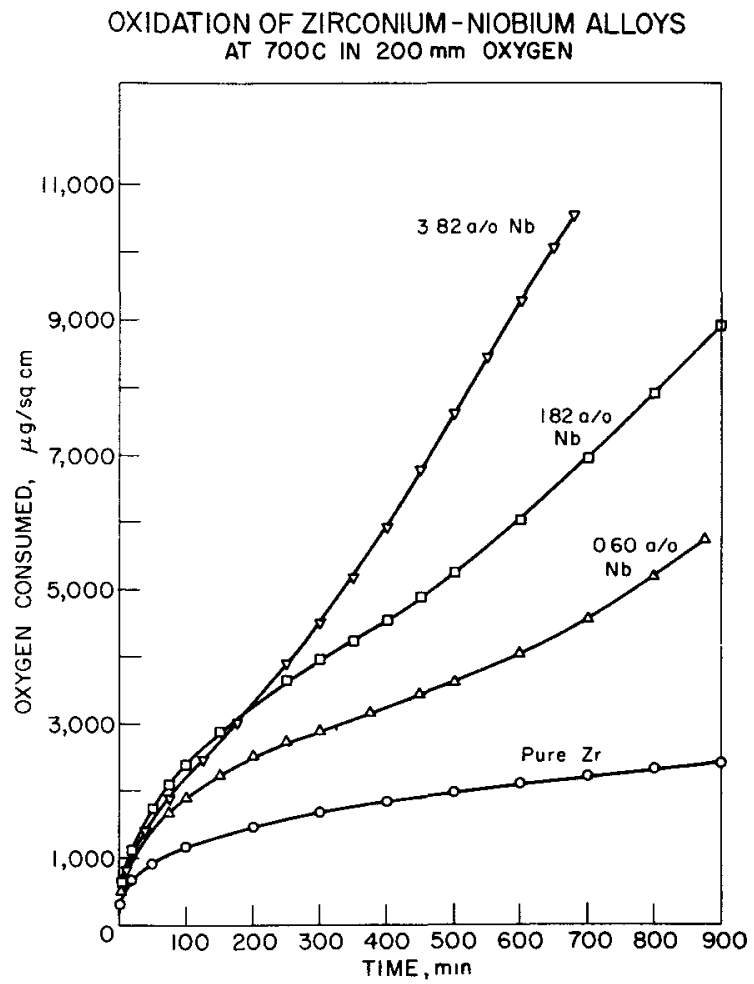

Figure 30

OXIDATION OF ZIRCONIUM - CARBON ALLOYS AT $700 \mathrm{C}$ IN $200 \mathrm{~mm}$ OXYGEN

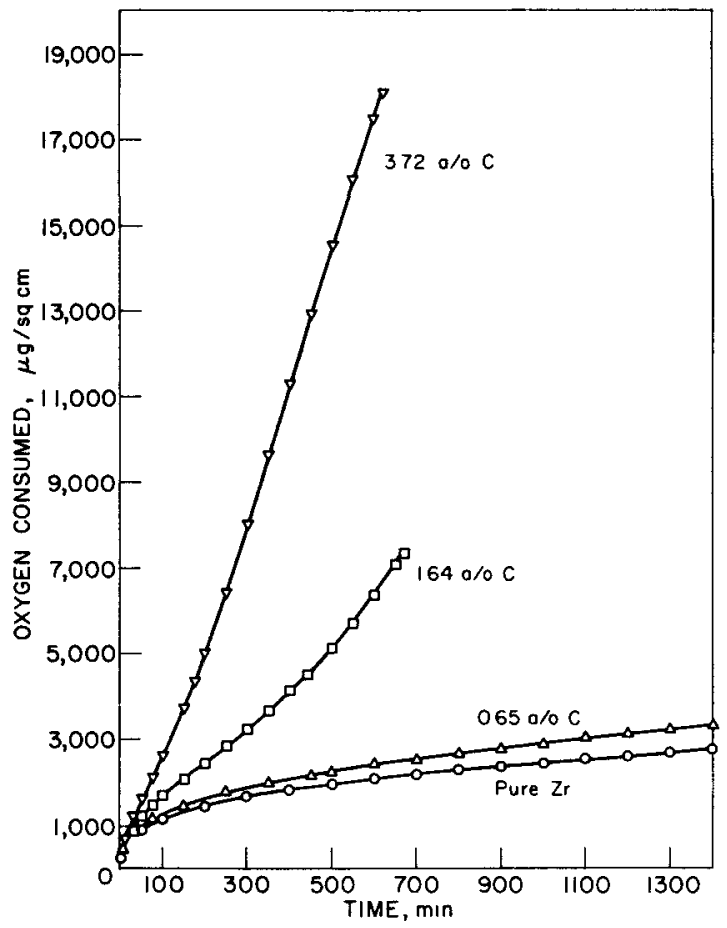

Figure 32

OXIDATION OF ZIRCONIUM - TITANIUM ALLOYS AT $700 \mathrm{C}$ IN $200 \mathrm{~mm}$ OXYGEN

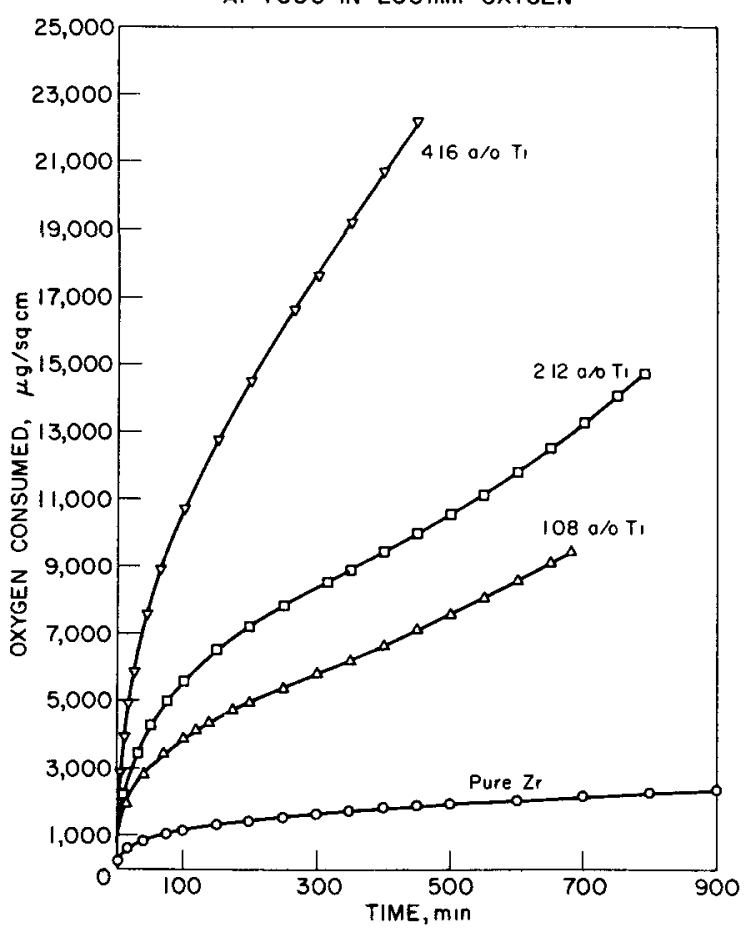

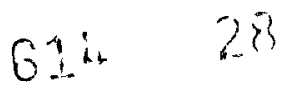


These figures also distinguish between the various degrees of breakaway phenomena, since this cannot be done in a table. For instance, in the zirconium-tin system (Figure 25) the breakaways are distinct and obvious, while in the zirconium-titanium system (Figure 32) the breakaways represent little more than gradual increases of the reaction rates.

The breakaway evidently takes place when the oxide film loses its protective character, but it does not appear to be related to any particular weight gain, since breakaway weights ranging from 439 to $15,975 \mu \mathrm{g}$ per sq $\mathrm{cm}$ have been observed. The weight at which a particular alloy will show a breakaway is probably a complicated function of several factors, which will be discussed in the next section.

The color and character of the oxide films of alloys that had undergone breakaways (see Table VII) were definitely different from those of the proteçtive oxide films on other alloys (see Table VI). For alloys where no breakaway occurred, the oxide films were usually gray or black and very adherent. In contrast, the oxide films for the majority of alloys where breakaway had occurred were light colored and some readily flaked off.

Of the twenty binary alloy systems investigated only the copper, nickel, beryllium, and hafnium alloys showed any increased resistance to oxidation as compared with pure zirconium.

\section{DISCUSSION}

\section{A. Literature and Theoretical Considerations}

The general characteristics of the oxidation of zirconium and zirconium-base alloys were (1) an initial stage in which the rate of oxygen consumption decreased with time, and (2) a certain thickness of oxide at which the film loses its protective properties, leading to a faster, essentially linear rate of oxidation. For pure zirconium and most of the alloys the initial rate was cubic, although a few of the alloys showed an initial parabolic rate.

Several studies have been made to determine the mechanism of formation of the oxide film on zirconium. By employing inert markers it has been observed $(8,20)$ that the oxidation proceeds by oxygen (anion) migration through the oxide film toward the metal-metal oxide boundary. In another study $(21)$ it was reported that anodic oxidation of zirconium at room temperature under low electric fields also proceeds by anion migration through the zirconium dioxide.

Consideration of the size of oxygen ions shows that they a re too large to occupy interstitial positions in the zirconium oxide lattice. Therefore, it may be concluded, at least in thin films without cracks, that anion diffusion takes place by lattice defects or holes. 
Measurements of thermoelectric power* on films of pure zirconium and zirconium-tin alloys gave negative values. (8) Thus, it may further be concluded that these films were anion-deficit semiconductors (n-type).

According to the Wagner-Hauffe semiconductor approach to alloy oxidation, foreign ions of lower valency than that of zirconium should increase the rate of oxidation, since they create more lattice defects. Conversely, ions of valency higher than that of zirconium should reduce the concentration of oxygen ion defects and thus decrease the oxidation rate. Although this theory was derived for oxidation obeying the parabolic rate law, it is not necessarily limited to this, since it has been found to apply to the case of zinc, which followed a logarithmic rate law.(22)

A few attempts have been made to provide a theoretical basis for the cubic rate equation. Mott $(23,24)$ derived a cubic rate equation based on the premise that diffusion of cation vacancies is rate controlling, where the number of vacancies is proportional to the number of negative ions per unit surface area and to a linear field set up by the ions. Engell, Hauffe, and Ilschner (25) derived a similar equation based on migration of positive holes and diffusion of lattice vacancies. Both of these derivations were based on p-type oxide films. A different approach has been taken by Uhlig, (26) who recently derived a cubic rate equation based on electron flow from the metal as the controlling step in the oxidation process. This equation would be applicable for films of thickness up to several thousand Angstrom units. in which case the space charge in the oxide is important.

An attempt to explain the cubic oxidation of titanium has been made by Kofstad and Hauffe.(27) They suggested that, in view of the high solubility of oxygen in titanium, the cubic rate law could be interpreted in terms of diffusion of oxygen through the outer layer of oxygen-enriched titanium. Since zirconium also has a high oxygen solubility, it is probable that the cubic oxidations of zirconium and titanium follow a similar mechanism.

Thus, it is not altogether surprising that the oxidation of zirconium, which ostensibly proceeds by inward oxygen diffusion, does not obey the sim. ple parabolic rate law because the oxidation kinetics are complicated by oxygen dissolution in the outer layer of zirconium metal.

$*$

To determine the type of (electrical) conduction in a semiconductor it is necessary to make measurements of thermoelectric power. If the current is carried exclusively by electrons, then the thermoelectric power will be negative, whereas the thermoelectric power must be positive if the current is carried by the positive holes. 
B. Correlation of Isothermal Rate Data with Theory

A condition which must be met for the Wagner-Hauffe theory to apply is that the metal which is added to the zirconium must share in the film formation but must not give rise to the formation of a new phase. This condition has on occasion been expressed in terms of the solubility of the oxide of the added metal in zirconium dioxide. However, it is thought that a more appropriate way of expressing this condition is in terms of the original state of the metal added to alpha zirconium before oxidation. Thus, if the added metal is in true solution in the metallic state, it is unlikely that segregation into two distinct oxide phases will occur on oxidation, even if the oxide of the added metal is insoluble in zirconium dioxide. This statement should be true for reasonably dilute alloys and for temperatures sufficiently low that the mobilities of the metal ions in the oxide phase are low. For the problem under immediate consideration both of these conditions are true.

In the case of a metal insoluble in alpha zirconium, the situation that probably exists in the alloy is that agglomerates of the second metal are randomly situated throughout the zirconium. Then, when oxidation occurs, these islands of alloying metal produce agglomerates of alloying metal oxide which tend to remain as a separate oxide phase. Since solubility equilibrium does not have an opportunity to be established in the oxide phase in experiments with the conditions of this study, it is believed that solubility data for the oxide systems are not germane.

In Table VIII are presented data for the alloy systems which were studied in this program and which are in the category of the additive metal being reasonably soluble (greater than 1 atom per cent). The Wagner-Hauffe theory should be applicable to these systems. In columns 2, 3, and 4 of Table VIII are presented the ratios of cubic rate constants for the alloys to that for zirconium. In column 7 the effects of the additives as predicted by the theory of Wagner-Hauffe are indicated and column 8 shows the observed effects. The last column indicates whether or not there is agreement with the prediction. Only for the case of lead does the prediction of the theory disagree with the experimental data. Lead is an exceptional additive in that its Goldschmidt ionic radius is 52 per cent greater than that of zirconium. All of the other additives considered in this table have ionic radii less than that of zirconium. The oxide of lead most likely formed, $\mathrm{PbO}$, is also the thermodynamically most unstable additive oxide of the series by many kilocalories. Therefore, for these two reasons lead can be considered unique.

The agreement of experimental results with predicted results is actually better than indicated by six examples out of seven. The phase diagrams in the literature indicate that copper, beryllium, cobalt, nickel, iron, chromium, silicon, platinum, vanadium, molybdenum, tungsten, uranium, and carbon are relatively insoluble in alpha zirconium at $700 \mathrm{C}$. These additives, therefore, should not necessarily follow the predictions of the 


\section{Prediction of Initial Oxidation Behavior of Zirconium Alloys}

Consideration restricted to (a) initial rate of oxidation at $700 \mathrm{C}$ in $200 \mathrm{~mm}$ oxygen and (b) experimental zirconium alloys where the solubility of the additive metal in alpha zirconium at $700 \mathrm{C}$ is greater than 1 a/o.

\begin{tabular}{|c|c|c|c|c|c|c|c|c|c|c|c|}
\hline \multirow{3}{*}{$\begin{array}{c}\text { Alloy } \\
\text { Additive } \\
\end{array}$} & \multirow{2}{*}{\multicolumn{6}{|c|}{$\begin{array}{c}\text { Rate Constant } \\
\text { Ratio } a, b\end{array}$}} & \multirow{3}{*}{$\begin{array}{l}\text { Solubility in } \\
\text { Alpha } \mathrm{Zr} \text { at } \\
700 \mathrm{C}(\mathrm{a} / \mathrm{o})\end{array}$} & \multirow{3}{*}{$\begin{array}{c}\text { Most Likely } \\
\text { Oxidation } \\
\text { Number } \\
\text { in Oxide } \\
\end{array}$} & \multirow{3}{*}{$\begin{array}{c}\text { Predicted by } \\
\text { Wagner-Hauffe } \\
\text { Theory } \\
\end{array}$} & $\begin{array}{l}\text { Additive } \\
\text { idation Rate }\end{array}$ & \multirow{3}{*}{$\begin{array}{c}\text { Agreement } \\
\text { with } \\
\text { Prediction } \\
\end{array}$} \\
\hline & & & & & & & & & & \multirow[b]{2}{*}{ Observed } & \\
\hline & \multicolumn{2}{|c|}{$1 \mathrm{a} / \mathrm{o}^{\mathrm{c}}$} & \multicolumn{2}{|c|}{$2 \mathrm{a} / \mathrm{o}^{\mathrm{c}}$} & \multicolumn{2}{|c|}{$4 \mathrm{a} / \mathrm{o}^{\mathrm{c}}$} & & & & & \\
\hline $\mathrm{Al}$ & 8.8 & B & 7.5 & B & 5.0 & B & 1.6 & 3 & Increase & Increase & Yes \\
\hline $\mathrm{Hf}$ & 0.88 & & 0.88 & & 0.88 & & miscible & 4 & No change & $\begin{array}{l}\text { Essentially no } \\
\text { change }\end{array}$ & Yes \\
\hline $\mathrm{Ti}$ & 4.4 & B & 157 & B & $\mathbf{P}$ & B & miscible & 2 & Increase & Increase & Yes \\
\hline Sn & 0.58 & B & 0.69 & B & 0.75 & B & 2 & 4 & No change & $\begin{array}{l}\text { Essentially no } \\
\text { change }\end{array}$ & Yes \\
\hline $\mathrm{Pb}$ & 0.69 & B & 1.0 & B & 0.50 & $\mathrm{~B}$ & 3 & 2 & Increase & $\begin{array}{l}\text { Essentially no } \\
\text { change }\end{array}$ & No \\
\hline $\mathrm{Nb}$ & 3.7 & B & $\mathrm{P}$ & B & 4.3 & $\mathrm{~B}$ & 3 & 2 & Increase & Increase & Yes \\
\hline $\mathrm{Ta}$ & $P$ & & $\mathrm{P}$ & & $\mathrm{P}$ & $\mathrm{B}$ & 5 & $2^{\mathrm{e}}$ & Increase & Increase & Yes \\
\hline
\end{tabular}

aRatio of cubic rate constant of alloy to that for pure zirconium except where symbol "p" indicates oxidation followed parabolic rate law rather than cubic; in the latter cases the oxygen consumed per unit time is greater than that for pure zirconium for the period of the experiment.

bSymol "B" indicates breakaway phenomenon during period of observation.

${ }^{c}$ Nominal concentrations. For exact concentrations see Table II.

dPredicted from free energy of formation at $973 \mathrm{~K}$ per gram-atom of oxygen from data compiled by Gl assner, A., ANL-5750 (1957).

experimentally demonstrated that $\mathrm{TaO}$ formed when Ta reacts with $\mathrm{ZrO}_{2}$ at $1700 \mathrm{C}$ [Chupka, W. A., Berkowitz, J., and Ingram, M. G., J. Phys. Chem. 26, 207 (1957)]. 
valence effect of Wagner-Hauffe theory. In the thirteen cases cited, eleven do not follow the prediction and only two (vanadium and iron) follow the prediction. However, the oxide of vanadium, $\mathrm{V}_{2} \mathrm{O}_{5}$, has a low melting point $(675 \mathrm{C})$ and thus is not typical. The other additive (iron) shows a slightly increased rate of oxidation which follows the prediction despite the very low solubility in zirconium.

Among the additives studied which were soluble in zirconium, none increased the oxidation resistance as the theory would predict, because none had oxidation numbers higher than four. Five additives which were not studied - technetium, rhenium, ruthenium, osmium, and iridium - have oxidation numbers greater than four, but of these only ruthenium has been found to have an appreciable solubility in alpha zirconium. The solubilities of the other four are unknown.

It therefore seems appropriate to look amang the metal additives not soluble in zirconium, for which the Wagner-Hauffe theory does not apply, for the additives which might significantly increase oxidation resistance. However, among the insoluble additives studied, none showed a significant increase in oxidation resistance and only the copper, nickel, and beryllium additives showed even a slight increase. In seeking to explain the effects of additives which do not follow the Wagner-Hauffe theory on the oxidation rate, it is necessary to consider the properties of the individual oxides concerned. These properties might be preferential oxidation relative to zirconium, protective nature of the oxides, diffusion rates of ions in the oxides, and electrical conductivities of the oxides.

\section{Breakaway Phenomenon}

After a period of time many of the alloys studied have exhibited an acceleration in the oxidation kinetics. This so-called "breakaway" or "transition" previously has been observed $(3,8,9,13,28)$ to occur during the oxidation of zirconium and zirconium alloys. The interpretation given to the breakaway has been that, since the volume ratio of zirconium dioxide to zirconium is 1.5 , the oxide grows under compressive strain and, at a certain film thickness, cracks to release the compression, thus leading to the breakaway.

In one study (29) concerned with the growth of oxide films on zirconium in high-temperature water, it was reported that an initial film of tetragonal zirconium dioxide transformed to the monoclinic oxide after which the corrosion proceeded at an accelerated rate.

In a recent electron-diffraction and kinetic study(28) of the oxidation of zirconium and some of its alloys with aluminum, tin, and titanium in air it was proposed that the breakaway is associated with a phase transformation in the film of zirconium dioxide. According to the theory advanced, the initial film formed on zirconium is the cubic polymorph of zirconium 
dioxide. As the oxidation progresses the film transforms to the tetragonal and finally to the monoclinic (stable) form of zirconium dioxide. The breakaway, it was reported, takes place when the last transformation is observed.

To test this hypothesis and to obtain a better understanding of the mechanism of oxide film growth on zirconium alloys, electron and X-ray diffraction analyses have been obtained on oxidized zirconium alloy samples.

The oxide structures observed on 16 different alloys after oxidation to selected extents are presented with the oxidation data in Table IX. Typical electron diffraction patterns are presented in Figure 33 for five cases, all oxidized less than the breakaway weight ( $A$, face-centered cubic structure on $2.12 \mathrm{a} / \mathrm{o}$ titanium alloy; $\mathrm{B}$, face-centered cubic structure plus an unknown phase on $3.60 \mathrm{a} / \mathrm{o}$ copper alloy; $\mathrm{C}$, unknown body-centered cubic structure on 3.52 a/o uranium alloy; D, unknown body-centered cubic structure plus unknown phase on 1.82 a/o niobium alloy; and $E$, monoclinic structure on $3.88 \mathrm{a} / \mathrm{o}$ vanadium alloy).

Of the 14 samples examined after less oxidation than the breakaway weight, 9 showed the face-centered cubic structures (three of which had another unknown phase), two showed an unknown body-centered cubic structure, and three showed the monoclinic structure.

Of the ten samples oxidized beyond breakaway, four showed the facecentered cubic structure (two of which had another unknown phase) and six showed the monoclinic structure.

Although a majority of the alloys showed a relationship between the oxidation kinetics and the change of structure of the oxide film, careful consideration of the data show enough exceptions to the predicted sequence of polymorphic transformations to make it clear that there is no rule which is applicable a priori to all zirconium alloy systems. Some of the unidentified phases found may be secondary or ternary compounds with the alloying element. To identify the unknown phases would involve an extended research program beyond the scope of this investigation.

These results show that the predicted sequence of phase transformations in the zirconium dioxide film and the relationship to the oxidation kinetics as outlined above is probably an oversimplified explanation which may be applicable for pure zirconium and some zirconium alloys but cannot be extended to include all zirconium alloys.

Undoubtedly, these polymorphic transformations are brought about by several interrelated effects which change in relative importance with different impurities in the metal. For pure zir conium the following oversimplified process may take place. Initially, a thermodynamically unstable film of cubic zirconium dioxide is formed. The film grows under large compressive strain and, since it is extremely adherent to the metal

$$
6 \div \quad 34
$$


TABLE IX

Oxide Phases on Oxidized Zirconium Alloys

(Oxidized at $700 \mathrm{C}$ in $200 \mathrm{~mm}$ oxygen for extent tabulated; evacuated, cooled, and examined)

\begin{tabular}{cccc} 
Alloy & $\begin{array}{c}\text { Extent of } \\
\text { Oxidation } \\
(\mu \mathrm{g} / \mathrm{sq} \mathrm{cm})\end{array}$ & $\begin{array}{c}\text { Breakaway } \\
\text { Weight } \\
(\mu \mathrm{g} / \mathrm{sq} \mathrm{cm})\end{array}$ & $\begin{array}{c}\text { Observed Oxide } \\
\text { Phase }\end{array}$ \\
\hline
\end{tabular}

Oxidation Terminated Prior to Breakaway

$\begin{array}{llrl}\text { Pure } \mathrm{Zr} & 2832 & -\mathrm{c} & \mathrm{fcc} \\ 1.96 \mathrm{~W} & 5787 & -\mathrm{c} & \mathrm{fcc} \\ 4.22 \mathrm{Pt} & 1128 & 1763 & \mathrm{fcc} \\ 1.42 \mathrm{Al} & 1071 & 1467 & \mathrm{fcc} \\ 3.72 \mathrm{C} & 783 & 1076 \mathrm{p} & \mathrm{fcc} \\ 2.12 \mathrm{Ti} & 2508 & 9468 & \text { fcc d } \\ 4.16 \mathrm{Ti} & 3957 & 15975 \mathrm{p} & \text { fcc plus unknown } \\ 3.60 \mathrm{Cu} & 2385 & -\mathrm{c} & \text { fcc plus unknown } \\ 1.78 \mathrm{Ta} & 11688 & -\mathrm{c} p & \text { fcc plus unknown } \\ 3.88 \mathrm{~V} & 3392 & -\mathrm{c} p & \text { monoclinicd } \\ \pi & 14392 & -\mathrm{c} p & \text { monoclinice } \\ 4.08 \mathrm{Hf} & 2634 & - & \text { monoclinic } \\ 3.52 \mathrm{U} & 1398 & 2645 & \text { unknown bcc } \\ 1.82 \mathrm{Nb} & 1894 & 5625 \mathrm{p} & \text { unknown bcc plus unknown }\end{array}$

Alloys Oxidized Beyond Breakaway

$\begin{array}{rrrl}4.22 \mathrm{Pt} & 3292 & 1763 & \text { fcc } \\ 2.12 \mathrm{Ti} & 14770 & 9468 & \text { fcc plus unknown } \\ 4.16 \mathrm{Ti} & 23402 & 15975 \mathrm{p} & \text { fcc plus unknown } \\ 3.60 \mathrm{Sn} & 1343 & 521 & \text { fcc } \\ \pi & 13404 & \pi & \text { monoclinic } \\ 3.52 \mathrm{U} & 4139 & 2645 & \text { monoclinic } \\ 1.94 \mathrm{Si} & 22435 & 1650 \mathrm{p} & \text { monoclinic } \\ 1.64 \mathrm{C} & 10845 & 1225 & \text { monoclinic } \\ 1.42 \mathrm{Al} & 24780 & 1467 & \text { monoclinic } \\ 3.54 \mathrm{Ta} & 15727 & 7830 & \text { monoclinic }\end{array}$

${ }^{a}$ Determined in previous oxidation studies at $700 \mathrm{C}$ in $200 \mathrm{~mm}$ oxygen (see Table VII). Initial oxidation follows cubic rate law unless indicated as parabolic by letter p.

$b_{f c c}=$ face-centered cubic structure; $a_{0}$ between 5.37 and $5.61 \mathrm{~A}$ $\left(a_{0}\right.$ for fcc $\mathrm{ZrO}_{2}=5.07 \mathrm{~A}$ )

$\mathrm{bcc}=$ body-centered cubic structure; $\mathrm{a}_{0}=3.16 \mathrm{~A}\left(\mathrm{a}_{0}\right.$ for $\left.\mathrm{bcc} \beta \mathrm{Zr}=3.62 \mathrm{~A}\right)$ Electron diffraction by glancing from oxidized parallelepiped surface; interpretation by $\mathrm{H}$. Knott and M. Mueller, Metallurgy Division.

${ }^{c}$ No breakaway observed for 1400 -min oxidation.

dElectron diffraction patterns presented in Figure 10 ,

e Determined by X-ray diffraction of powder removed from surface. Interpretation by D. S. Flikkema, Chemical Engineering Division. 


\section{FIGURE 33}

\section{ELECTRON DIFFRACTION PATTERNS FROM SELECTED}

OXIDES ON ZIRCONIUM ALLOYS

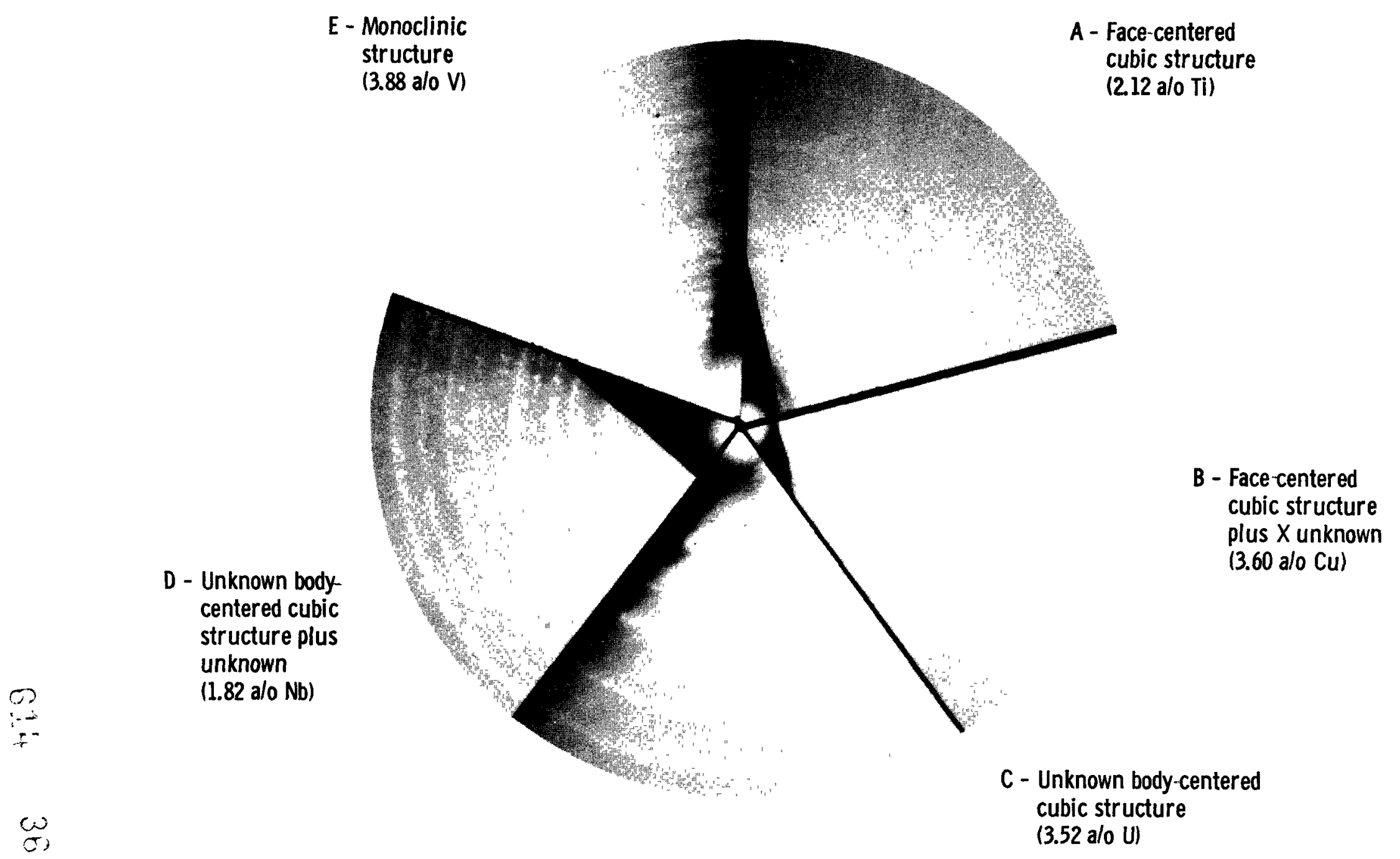


substrate, it is protective in nature. At a critical thickness the compressive strains become too great and must be relieved by the transformation of the oxide film to the tetragonal and, finally, to the monoclinic form. Coincident with the last transformation, the film loses its protective properties and a faster rate of oxidation ensues.

When certain metallic impurities which are soluble in zirconium are added, the oxidation process produces a film which consists of the additive metal oxide dispersed in cubic zirconium dioxide. If the ionic radius of the additive ion is sufficiently different from the ionic radius of zirconium, the lattice of zirconium dioxide will be distorted. This will decrease the stability of the cubic form, thereby causing the polymorphic transformation to occur at a lower thickness of film than is the case with pure zirconium.

As an extension of this reasoning, a general rule, which appears useful in predicting the occurrence of the breakaway phenomenon, was formulated. This rule is that a breakaway will occur when the Goldschmidt ionic radius of the additive element differs by 15 per cent or more from the ionic radius of zirconium.

In the case of additives for which it is predicted that the WagnerHauffe theory is followed, all seven additives (19 out of 21 alloy compositions) follow the rule. These are alloys of aluminum, hafnium, titanium, tin, lead, niobium, and tantalum (see Table X). Tantalum, which is predicted to show a breakaway phenomenon, does so only in the highest concentration. It is quite likely, however, that the 1 and 2 atom per cent runs were not carried out long enough to observe the breakaway phenomenon. If breakaway can be as sumed to occur later, then the agreement is shown for all of these 21 alloys.

When metallic impurities which are insoluble in zirconium are added, the oxidation film consists of cubic zirconium dioxide and separate agglomerates of the additive metal oxide. Under certain conditions the separate oxide agglomerates may interfere with the adherency of the fllm to the metal; this would in turn cause polymorphictransformation in the zirconium dioxide film and thus bring about faster oxidation rates. The additives which are insoluble in alpha zirconium do not follow the Wagner-Hauffe theory for oxidation of alloys. However, these insoluble additives show good agreement with the rule relating the occurrence of breakaway with additive ionic radius. Of the thirteen insoluble additives, ten follow the rule: four in all three concentrations, four in the 2 and 4 atom percent concentrations, one in the 1 and 2 atom per cent concentration, and one in the 4 atom per cent concentration (see Table X). From the trend of breakaway time versus additive concentration in the case of uranium and silicon (see Table VII), it is possible that the runs on the lower concentrations of these additives were not carried out long enough to observe a breakaway. This agreement with the rule predicting breakaway is particularly remarkable since the factors causing breakaway are probably different for the insoluble and soluble additive systems. 
In order to understand better the mechanism of oxide film growth on zirconium, more information concerning the nature of the film must be obtained. The most promising way of accomplishing this appears to be through further electron diffraction studies of oxide films.

\section{SUMMARY}

The oxidation of zirconium was investigated in the temperature range from 400 to $900 \mathrm{C}$ at oxygen pressures of 50,200 , and $800 \mathrm{~mm}$. The

zirconium specimens were machined parallelepipeds, $1 \times 1 \frac{1}{2} \times 2 \mathrm{~cm}$. The reaction rates under all conditions were best expressed by the cubic rate law, $W^{\mathbf{3}}=\mathrm{kt}$, where $\mathrm{W}$ is the weight gain, $t$ is the time, and $k$ the rate constant.

At an oxygen pressure of $200 \mathrm{~mm}$ the activation energy was calculated to be $42.7 \pm 0.7 \mathrm{kcal}$ per mole, and the cubic rate constant in ( $\mu \mathrm{g}$ per sq $\mathrm{cm})^{3}$ per minute could be expressed as

$$
\mathrm{k}=\left(5.94 \times 10^{16}\right) \mathrm{e}^{-42,700 / \mathrm{RT}} \text {. }
$$

The effect of surface preparation on the reaction rate was investigated in the temperature range from 400 to $700 \mathrm{C}$. The standard method of preparation of samples was wet polishing through 600-grit silicon carbide paper. When the samples were chemically polished, the reaction rate in the temperature range from 400 to $600 \mathrm{C}$ was still best expressed by the cubic rate law. However, the rate constants obtained from chemically polished samples were slightly lower than those obtained from mechanically polished samples. The reaction rate at $700 \mathrm{C}$ was found to be even less sensitive to sample pretreatment.

The effect of pressure was determined by investigating the reaction at oxygen pressures of 50,200 , and $800 \mathrm{~mm}$. It was found that the oxidation rate was independent of pressure.

To study the effect of sample shape the oxidation of $0.25-\mathrm{mm}(10-\mathrm{mil})$ foil specimens was studied at $700 \mathrm{C}$. The cubic rate law was obeyed. However, the rate constants were slightly larger than values obtained from parallelepiped samples.

A study was made of the effect of additives on the oxidation of zirconium at $700 \mathrm{C}$ in $200 \mathrm{~mm}$ oxygen. The oxidation kinetics of a series of alloys of zirconium with aluminum, beryllium, carbon, chromium, cobalt, copper, hafnium, iron, lead, molybdenum, nickel, niobium, platinum, silicon, tantalum, tin, titanium, tungsten, uranium, and vanadium in the nominal concentrations of 1,2 , and 4 atom per cent were investigated. The alloys were classified into the following four groups, according to the type of oxidation behavior shown: 
Group I - those alloys which oxidized according to the cubic rate law and did not exhibit breakaway oxidation phenomena (pure zirconium oxidized in this manner);

Group II - those alloys which oxidized according to the parabolic rate law and did not exhibit breakaway oxidation phenomena;

Group III - those alloys which oxidized initially according to the cubic rate law but later exhibited breakaway oxidation phenomena; and

Group IV - those alloys which initially oxidized according to the parabolic rate law but later exhibited breakaway oxidation phenomena.

The initial rates of oxidation of alloys of those additives which are soluble in alpha zirconium could be interpreted in terms of the WagnerHauffe theory of alloy oxidation. For these alloys, it was postulated that the oxidation product consisted of a single phase. The oxidation number of the additive element in the oxide affects the concentration of anion vacancies, which is directly related to the oxidation rate. This followed since the oxidation proceeded by anion diffusion through vacancies in the oxide lattice. In the case of additives insoluble in alpha zirconium, it was postulated that the oxidation produced agglomerates of alloying metal oxide which tend to remain as a separate oxide phase. For these alloys the WagnerHauffe theory did not apply.

The breakaway phenomenon may be predicted by the rule that a breakaway will occur when the ionic radius of the additive element in the oxide differs by 15 per cent or more from the ionic radius of zirconium. This rule was followed by all seven of the alloys which obeyed the WagnerHauffe theory. Even though the factors causing breakaway are probably different for the insoluble and soluble additive systems, the rule also was followed by ten of the thirteen insoluble additives.

Some X-ray and electron diffraction studies were made which indicate that for zirconium and some of its alloys the breakaway occurs as a result of the transformation from cubic to monoclinic zirconium dioxide.

\section{ACKNOWLEDGEMENTS}

The assistance in the laboratory of A. Porter, and of student aides, $V$. Sidhu and P. Tonne, is gratefully acknowledged. The authors are indebted to V. H. Munnecke for assistance in procurement of the alloys, D. S. Flikkema for X-ray diffraction analyses, and H. Knott and $M$. Mueller for electron diffraction studies.

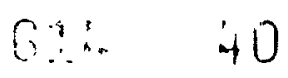




\section{REFERENCES}

I. Gulbransen, E. A., and Andrew, K. F., J. Metals 1, 515 (1949)

2. Belle, J., and Mallett, M. W., J. Electrochem. Soc. 101, 339 (1954)

3. Gulbransen, E. A., and Andrew, K. F., J. Metals 9, 394 (1957)

4. Cubicciotti, D., J. Am. Chem. Soc. 72, 4138 (1950)

5. Fassell, M. W., NP-4246 (1952)

6. Garibotti, D. J., Green, H. M., and Baldwin, W. M., Jr., AECU-3013 (1955)

7. Kofstad, P., Acta Chem. Scand. 12, 701 (1958)

8. Mallett, M. W., and Albrecht, W, M., J. Electrochem. Soc. 102, 407 (1955)

9. Gulbransen, E. A., and Andrew, K. F., Trans. AIME 212, 281 (1958)

10. Hayes, E. T., and Roberson, A. H., Trans. Electrochem. Soc. 96, 142 (1949)

11. Dravnieks, A., J. Am. Chem. Soc. $\underline{72}, 3568$ (1950)

12. Mallett, M. W., Belle, J., and Cleland, B. B., J. Electrochem. Soc. $101,1(1954)$

13. Kendall, L. F., Wheeler, R. B., and Bush, S. H., Nucl. Sci. Eng. $\underline{3}$, 171 (1958)

14. Phalnikar, C. A., and Baldwin, W. M., Jr., Proc. Am. Soc. Testing Materials, 51, 1038 (1951)

15. Litton, F. B., and Ogburn, S. L., AF-TR-5943 (1940)

16. Anderson, C. T., Hayes, E. T., Roberson, A. H., and Kroll, W. T., BM-RI-4568 (1950)

17. Burka, J. A., Crouse, C. S., and Swift, R. E., AECU-3661 (1957)

18. ASM Symposium, "Zirconium and Zirconium Alloys," Cleveland (1953)

19. Lustman, B., and Kerze, F., Jr., Metallurgy of Zirconium, McGrawHill Book Co., Inc., New York (1955), pp. 610 and 625

$$
6 \therefore \quad 4 i
$$


20. Chirigos, J., and Thomas, D. E., WAPD-53 (1952)

21. Flint, O., and Varley, J. H. O., Nature 179, 145 (1957)

22. Vernon, W. H. J., Akeroyd, E. I., and Stroud, E. G., J. Inst. Met. 65, 301 (1939)

23. Mott, N., Trans. Faraday Soc. $\underline{36}, 472$ (1940)

24. Cabrera, N., and Mott, N. F., Rept. on Prog. in Physics 12 , 162 (1949)

25. Engell, H., Hauffe, K., and Ilschner, B., Z. Electrochem. $\underline{58}, 478$ (1954)

26. Uhlig, H. H., Acta Metall. 4, 541 (1956)

27. Kofstad, P., and Hauffe, K., Werkstoffe und Korrosion ?, 642 (1956)

28. Korobkov, I. I., Ignatov, D. V., Yevstyukhin, A. I., and Yemelyanov, V.S., Proceedings of the Second International Conference on Peaceful Uses of Atomic Energy, Geneva (1958), Paper P/2054

29. Schwartz, C. M., Vaughan, D.A., and Cocks, G.C., BMI-793 (1952) 